\author{
Ingrid Sahk
}

\title{
AUS DORPAT (TARTU) NACH ITALIEN UND ZURÜCK. ÜBER DIE BILDUNGSREISE WOLDEMAR FRIEDRICH KRÜGERS VERMITTELT DURCH DIE AN KARL EDUARD VON LIPHART VON 1832 BIS 1834 GESANDTEN BRIEFE
}

Woldemar Friedrich Krügers (1808-1894) Briefe an Karl Eduard von Liphart (1808-1891) aus den Jahren 1832 bis 1834 bieten uns einen kurzen, doch bedeutungsvollen Zeitausschnitt aus der Kunstgeschichte des 19. Jahrhunderts. Den Künstler Krüger sowie den Kunstsammler und Kunsthistoriker von Liphart verband eine lange Freundschaft, womit auch eine finanzielle Unterstützung für Krügers Ausbildung und Schaffen einherging. Beide, sowohl der Verfasser als auch der Empfänger der Briefe, waren damals junge Männer, somit handelte es sich vor allem um eine Periode der Bildung und der Selbstfindung. Die in den Schreiben aufzufindenden Stichworte, Namen und Daten ergänzen Krügers Münchener Jahre und bieten einen spannenden und tiefen Einblick in den Werdegang des Künstlers. Die als Quellenpublikation veröffentlichten Briefe stammen aus dem in der Dokumentensammlung des Marburger Herder-Instituts aufbewahrten Familienarchiv der von Lipharts ${ }^{1}$, mit dem uns zuvor Dorothee M. Goeze bekannt gemacht hat und das auch wichtige Quellenmaterialien zur Erforschung der

DOI: http://dx.doi.org/10.12697/BJAH.2016.12.05

Übersetzung aus dem Estnischen von Marju und Olaf Mertelsmann.

1 Dokumentensammlung des Herder-Instituts Marburg (DSHI), 110 Liphart II, 1-9. 
Kunstsammlung von Karl Eduard von Liphart enthält. ${ }^{2}$ Das Ziel des folgenden, knappen Einleitungstextes besteht vor allem darin, die Briefe im Zusammenhang von Krügers Lebenslauf zu verorten. Ebenso werden einige Themenbereiche eröffnet und verallgemeinert, die der Kommentatorin als bedeutungsvoll erschienen. Sowohl in der Einführung als auch in den Kommentaren der Briefe sind bezüglich des Lebens und der Tätigkeit von Woldemar Krüger die von Eha Ratnik erstellte Biografie sowie die Erinnerungen von Woldemar Krügers Sohn, Karl Krüger, genutzt worden. ${ }^{3}$

Im Jahr 1832, als die Briefe aus München einsetzten, hatte Woldemar Krüger das Gymnasium und eine kurze Studienzeit an der Kaiserlichen Universität zu Dorpat absolviert und vor ihm lag der erste, längere Aufenthalt im Ausland. Die Freundschaft mit dem Sohn des Gutsherrn von Gut Ratshof (Raadi), Karl Eduard, hatte bereits während der Schulzeit Krügers in Dorpat begonnen, als der Sohn des estnischen Speicherverwalters als Spielkamerad für den Sohn des Gutsherren von Ratshof, dem Landrat Karl Gotthard von Liphart, ausgewählt wurde. Die enge Beziehung mit dem Kindheitsfreund, dem zukünftigen Kunstkenner und Kunstsammler Karl Eduard von Liphart ${ }^{4}$, dauerte bis an Krügers Lebensende und beeinflusste stark sein künstlerisches Leben. Das künstlerische Talent war Krüger angeboren, doch bei der Herausbildung des Berufs spielten sicherlich die kunstverliebte Umgebung von Gut Ratshof und natürlich auch das Mäzenatentum der von Lipharts eine Rolle. Nach der Immatrikulation an der Universität Dorpat konnte Krüger auch am Unterricht der Zeichenschule der Universität teilhaben, die von Karl August Senff (1770-1838) geleitet wurde. Der Zeichenunterricht an der

2 Dorothee M. Goeze, ,., Von der Pflicht, anregend, fördernd auf das geistige Leben seiner Mitbürger einzuwirken.” Die Familie von Liphart im Spiegel ihres Archivs im Herder-Institut Marburg", Jahrbuch des baltischen Deutschtums, Bd. 56 (2009), hrsg. von der Carl-Schirren-Gesellschaft e. V. (Lüneburg, 2008) 3 (1972), 120-132. Fha Ratnik hoonistuskool. Woldemar Kruger, Tartu Kunstimuuseumi Almanahh, Krüger so - 132. Eha Ratnik hat als Quelle die Ering Beide Quellen werden ebenfalls für die folgende Übersicht verwendet. Karl Krü̈ser Aus Dor Beide Quellen werden ebenfalls für die folgende Ubersicht verwendet. Karl Krüger, „Aus Dorpats vergangenen Tagen", St. Petersburger Zeilung, 1. und 2. August 1898; Eesti Kultunrloolne Arhiiv / . Karl Krugers Manus ", Erinnerungen an Woldenar Kruger".

Zu Karl Eduard von Lipharts Leben und seiner Tatigkeit siehe beispielsweise Ingrid Sahk "Kingituseks jareltulevatele pôlvedele. Liphartite graafikakogust Raadi môisas ja Tartu ülikoolis" Unistuste Raadi. Liphartite kunstikogu Eestis = Raadi of Our Dreams. The Liphart Family and their Art Geteilte Freude und gelehrsme Kunde. Über. Tie Graphiksal Kmlung und die kïnstlich im Haus des Kunstkenners Karl Eduard von Liphart", Baltic Journal of Art History, 6 (2011), 303-328.

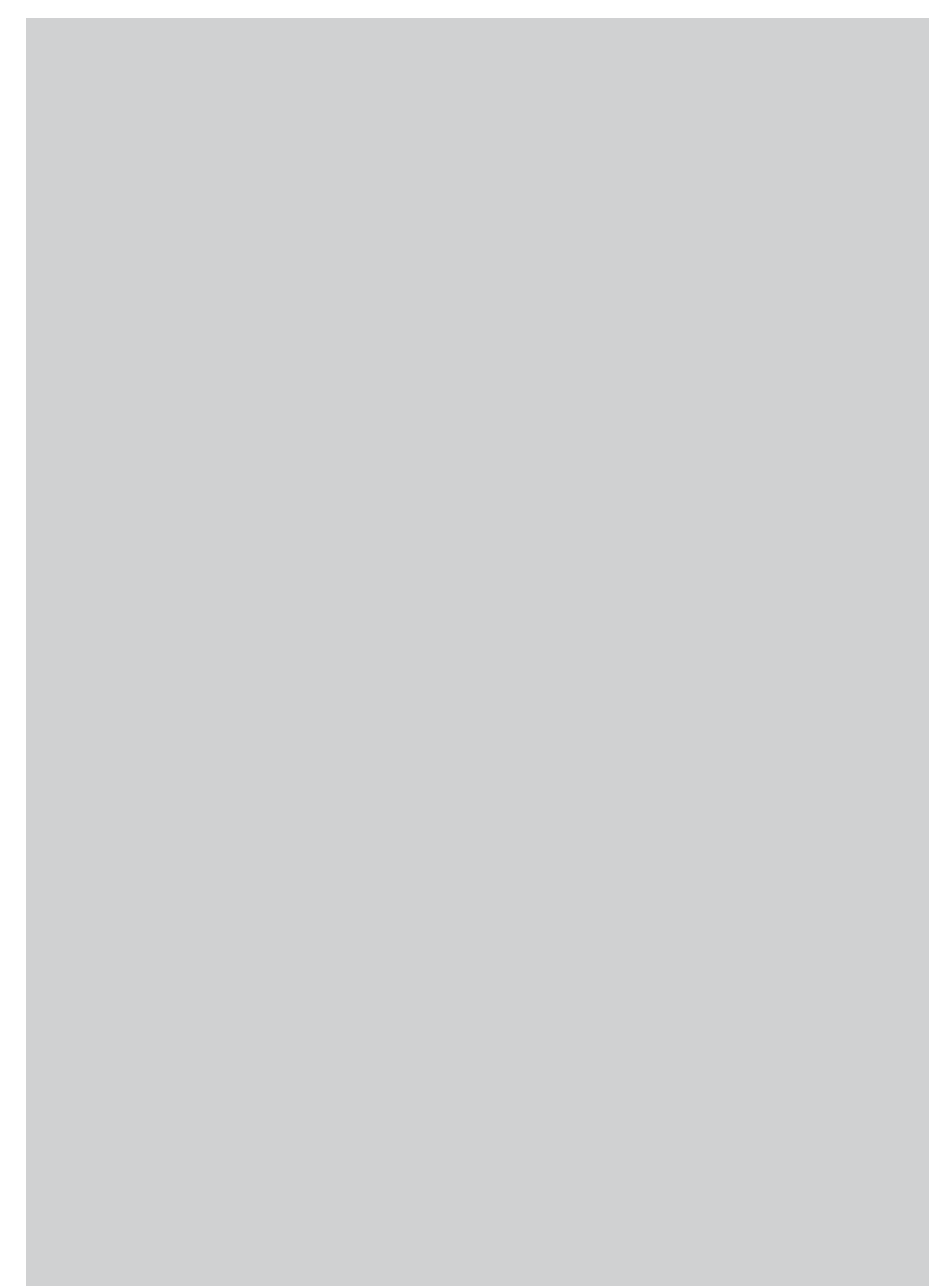

Abb. 1. Woldemar Krüger, Selbstporträt, Schwarze Kreide. Kunstmuseum Tartu. 
Universität musste auf einem hohen Niveau erfolgen und Krüger ein fleißiger Schüler sein, denn bereits im Jahr 1828 erhielt Krüger (zusammen mit anderen Kommilitonen, darunter August Matthias Hagen) die Aufgabe, die wissenschaftlichen Arbeiten des Professors der Botanik der Universität Dorpat, Karl Friedrich von Ledebour, zu illustrieren. ${ }^{5}$ Gerade diese feinen und klaren Aquarellen, gefertigt nach der Vorlage des Herbariums, welches Ledebour von einer Altai-Expedition mitgebracht hatte, verhalfen Krüger zu seiner Auslandsreise. Krüger erhielt für die Arbeit eines Illustrators ein ordentliches Honorar und wurde zum guten Bekannten von Professor von Ledebour, der gerade jetzt nach Deutschland reisen wollte und den jungen Kunstbegeisterten ermutigte, doch mitzukommen. Den Wunsch, sich in der Fremde fortzubilden, besaß Krüger seit langem, doch das Honorar für die Illustrationen reichte nicht für eine längere Reise und nur dank der Entscheidung der von Lipharts, Krüger für die Ausbildung in Deutschland ein jährliches Stipendium zu bezahlen, wurde die Reise verwirklicht. ${ }^{\circ}$

Damit verließ im Frühjahr des Jahres 1830 der junge Woldemar Krüger zusammen mit Professor Ledebour Dorpat. Mit Aufenthalten in Riga und Königsberg reisten sie gemeinsam weiter nach Berlin, dort trennten sich die Wege der beiden Dorpater und Krüger wandte sich nach Dresden, wegen der Bekanntheit der dortigen Kunstakademie. ${ }^{7}$ In Dresden hatte der Lehrer der Zeichenschule der Universität Dorpat, Karl August Senff, studiert (wohl nicht an der Kunstakademie), dieser könnte gerade diese Kunststadt empfohlen haben. Mit der Dresdener Kunstakademie waren auch andere in den Provinzen Estland und Livland tätige Künstler verbunden, beispielsweise die Brüder von Kügelgen, ebenso Carl Timoleon von Neff, der sein Studium in Dresden 1825 beendet hatte. Doch die Aufnahme eines Studiums in Dresden erwies sich für Krüger schwieriger als erwartet, worauf er beschloss, nach München zu gehen.

Der Weg von Dresden nach München verlief über Prag und Wien und hier war der älteste Sohn des Zeichenlehrers der Universität Dorpat Karl

5 Icones plantarum novarum vel imperfecte cognitarum, floram Rossicam, imprimis Altaicam, illustrantes. Centuria I, hrsg. von Carl Friedrich von Ledebour (Riga-London-Paris-StrassburgBrüssel, 1829). Vor der Abreise nach Deutschland erfüllte Krüger auch eine zweite Bestellung de Universität Dorpat und gestaltete den Atlas für Friedrich Georg Wilhelm Struves Werk „Beschreibun Kuslands

6 Krüger, „Aus Dorpats vergangenen Tagen .

. Treff $(1736-1813)$ nd Ludwig Richter (1803-1884).

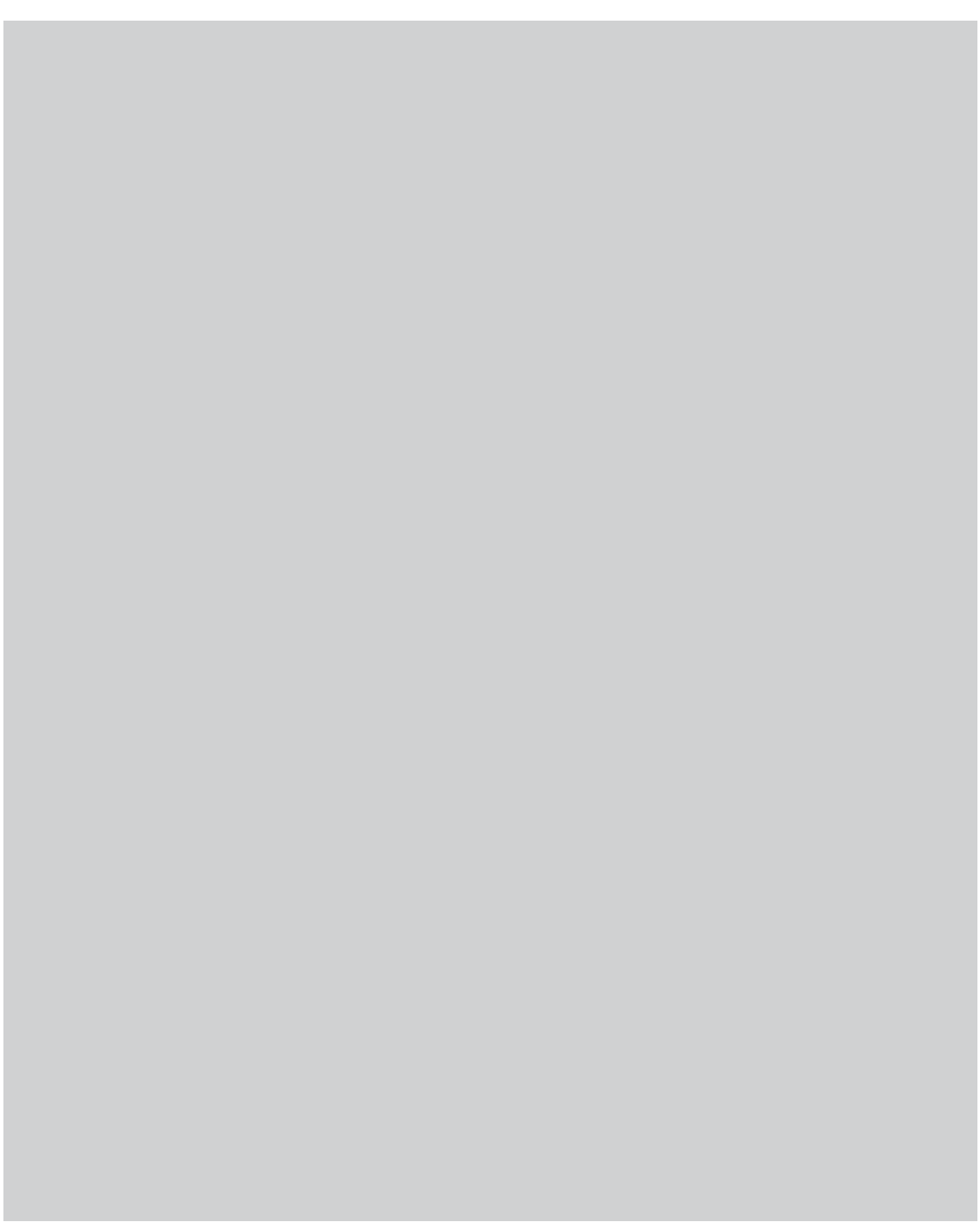

Abb. 2. Julius Senff, Karlstor in München, Bleistift, 1831. Estnisches Kunstmuseum.

August Senff, Karl Julius Senff (1804-1832), der Wegbegleiter Krügers, der sich für den Beruf des Architekten im Ausland fortbildete. Wie Karl Krüger sich erinnert hat, begannen die beiden jungen Männer mit 
Rucksäcken auf dem Rücken ihren Weg nach München. ${ }^{8}$ Wie sich das Reisen im 19. Jahrhundert abspielte, kann man aus den Reisetagebüchern und Erinnerungen anderer deutschbaltischen Künstler erfahren, die uns den Zauber und die Schwierigkeiten des damaligen Reisens übermitteln. ${ }^{9}$ Stets wollte man beim Reisen möglichst viele Eindrücke sammeln, oftmals diese als Zeichnungen und Entwürfe verewigen. Meist bewegte man sich zu Fuß fort, übernachtet wurde unter einfachsten Bedingungen. Auf dieser Art und Weise begegnete man unterwegs auch den alltäglichen Aspekten der fremden Kultur.

Im Herbst 1830 erreichte Woldemar Krüger bekannterweise München, Karl Julius Senff reiste weiter nach Italien ${ }^{10}$. Weil Krügers erste Briefe über die Ankunft in München nicht unter den im Herder-Institut deponierten Materialien sind, können wir es uns nur vorstellen, welche die ersten Eindrücke des jungen Kunstliebhabers waren und ob das Gesehene den Erwartungen entsprach. München war als Kunststadt im 19. Jahrhundert auf alle Fälle wichtig und ein einzigartiger Punkt auf Deutschlands Landkarte. Am lebendigen künstlerischen Leben der Hauptstadt des Königreichs Bayern hatte die Liebe der Künste der herrschenden Dynastie der Wittelsbacher einen entscheidenden Anteil. Die Münchener Kunstakademie wurde im Jahr 1808 unter der Herrschaft von Maximilian I. eröffnet (deren Vorgänger, eine Zeichenschule, war bereits seit dem Jahr 1770 aktiv gewesen). Mit einem besonderen Interesse an Kunst und dem Ziel, München als Kunststadt zu entwickeln, ging Ludwig I. in die Geschichte ein, auf dessen Initiative in München in der ersten Hälfte des 19. Jahrhunderts mehrere Museen eingerichtet worden sind. Als Krüger in München eintraf, war die zur Ausstellung von antiken Skulpturen erbaute Glyptothek (1816-1830, Leo von Klenze) bereits endgültig fertiggestellt. Begonnen hatte auch der Bau des Galeriegebäudes für die Gemäldesammlung der Wittelsbacher, die von Ludwig I. durch mehrere große Ankäufe ergänzt wurde, die sogenannte Alte Pinakothek (1826-1836, Leo von Klenze). Die Gemäldesammlung der Wittelsbacher war dennoch bereits früher teilweise für Interessierte zum Betrachten zugänglich gewesen und aus den Briefen ergibt sich, dass auch Krüger hingegangen ist, um sie anzusehen und seine Fähigkeiten

Krüger, „Aus Dorpats vergangenen Tagen”.

Siehe beispielsweise Leopold Pezold, Kolme Eestimaa kunstniku rännuaastad (Tallinn: Kunst, 1994); 1820-1821 (Tallinn: Eesti Ajaloomuuseum, 2011). 10 Karl Julius Senff verstarb 1832 unerwartet an einer Krankheit in Italien. beim Kopieren von Gemälden auszuprobieren. Ludwig I., der von 1825 bis 1848 regierte, unterstützte auch die Entwicklung der neuen Künste durch die Kunstakademie. Die Ausstellungen der Münchener Kunstakademie ermöglichten es Krüger, angesichts der Strömungen der zeitgenössischen deutschen Kunst im Bilde zu sein. Aus den Briefen kommt hervor, dass Krüger in näheren Kontakt mit den Bauarbeiten der Münchener Königsresidenz und den für diesen Zweck anzufertigenden Wandmalereien kam. Die Renovierungsarbeiten der königlichen Residenz der Wittelsbacher, die von Leo von Klenze (1784-1864) angeleitet wurden, verschafften vielen Künstlern Lohn und Brot, von denen für das Interieur mehrere Malereien bestellt wurden. Ludwig I. teilte die Begeisterung des Architekten von Klenze für antike Wandmalereien, und ähnliche, gerade in der Technik der Enkaustik (Wachsmalerei) ausgeführte Malereien wurden auch für mehrere Innenräume des Königspalasts der Wittelsbacher angefertigt.

Krüger erwartete in München auch mit Sicherheit, ob geplant oder nicht, ein Bekanntwerden mit der Praxis der Technik der Lithografie. München war nämlich die Geburtsstätte dieser grafischen Technik, welche die Bildkultur des 19. Jahrhunderts sehr stark veränderte. Noch im Jahr 1830, als die technischen Neuerungen und die Möglichkeiten des Farbdrucks bereits in den anderen europäischen Kunststädten Paris und Berlin weiterentwickelt wurden, war München wegen der lithografischen Druckereien wichtig. Ludwig I. nutzte gerade die Technik der Lithografie, um die Interessierten mit seinen Kunstsammlungen bekannt zu machen. Damit war München der geeignete Ort, um sich die nötigen Kenntnisse der lithografischen Technik anzueignen, und dies nutzte Krüger auch aus.

Es fehlt bisher eine klare Übersicht über die Studien Krügers in München. Ob Krüger an der Kunstakademie studierte, konnte bisher nicht belegt werden; es wird vermutet, dass er während seines Aufenthalts in München nicht regulär studierte. ${ }^{11}$ Leider bieten auch die Briefe in dieser Hinsicht keine ergänzenden Informationen. Krüger beklagt sich in seinem am 3. Dezember 1833 abgeschickten Brief wohl, dass für sein Schaffen wenig Zeit verbleibt, weil er sich zu viel mit der Nachahmung (dem Kopieren?) beschäftigen muss, doch ob diese Beschwerde im Zusammenhang mit der künstlerischen Ausbildung

11 Ratnik, „Tartu ülikooli joonistuskool. Woldemar Krüger”, 121. 


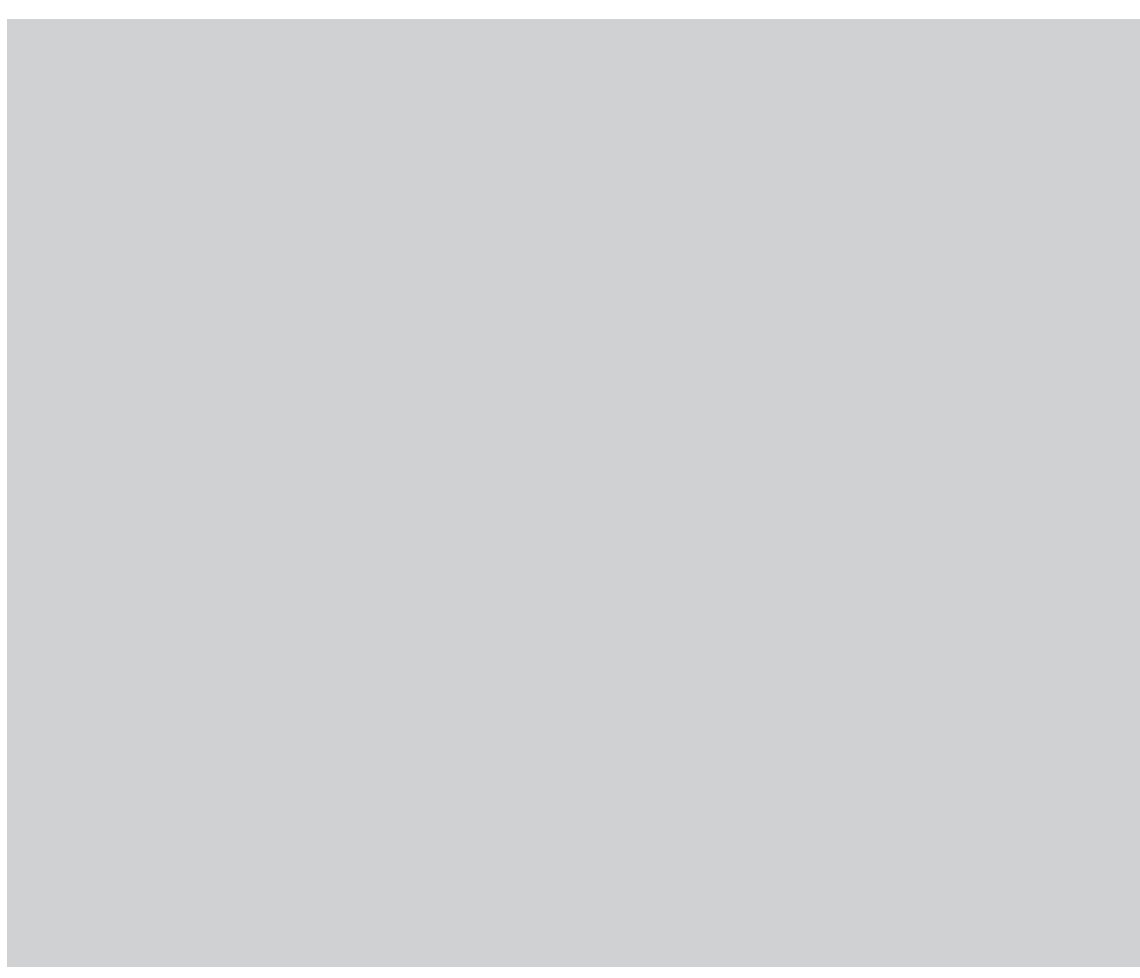

Abb. 3. Woldemar Krüger (nach Ferdinand Kobell?), Waldlandschaft, Lithographie, 1832 Kunstmuseum Tartu.

stand, bleibt ohne eine Erklärung. Zusätzlich zur Kunstakademie konnte in den dreißiger Jahren des 19. Jahrhunderts in München eine künstlerische Ausbildung auch an der Münchener Polytechnischen Schule erworben werden. Dort war Professor Joseph Anton Rhomberg (17861853) die zuständige Lehrkraft für das Zeichnen, in dessen Wohnung Krüger auch lebte. Auf Krügers mögliche Studien unter Anleitung von Professor Rhomberg wurde bereits früher schon hingewiesen ${ }^{12}$. Das sich in den Briefen eröffnende Interesse Krügers gerade für die Aneignung der praktischen künstlerischen Fertigkeiten erlaubt es, diese Vermutung zu unterstützen. Rhomberg vermittelte Krüger die Bekanntschaft mit dem Landschaftsmaler Carl Rottmann und sicher teilte er mit dem jungen Dorpater noch weitere notwendige Kontakte und nötiges Wissen. Es scheint so, dass unter den Möglichkeiten des Münchener Kunstlebens

12 Ratnik, „Tartu ülikooli joonistuskool. Woldemar Krüger”, 121.

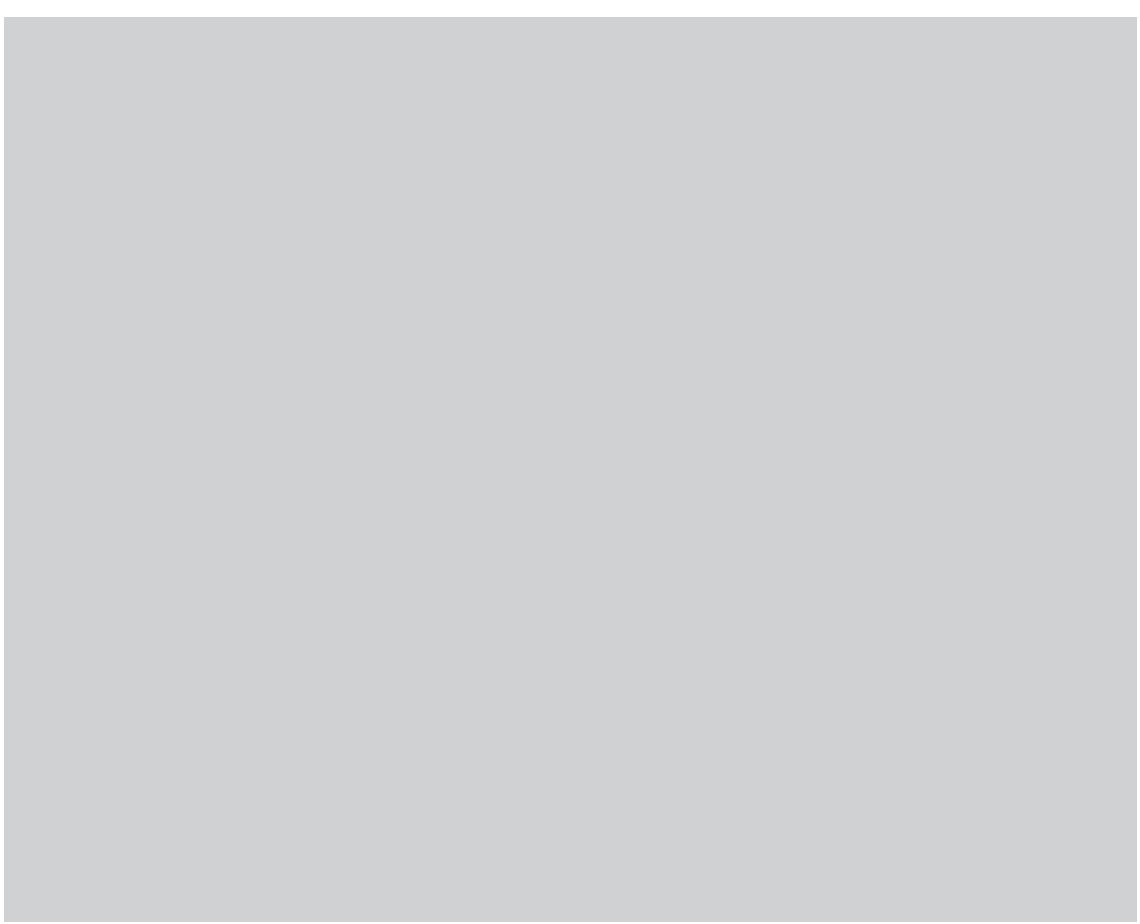

Abb. 4. Woldemar Krüger, Isola San Giovanni Lago Maggiore, Gouache, 1834. Kunstmuseum Tartu.

Krüger gerade die Weiterbildung auf dem Gebiet verschiedener praktischer Kunsttechniken nutzte. So eignete er sich in München neben den Arbeitsschritten und den Mitteln der lithografischen Technik auch die Fertigkeiten der Wachsmalerei an sowie die dafür passenden Farben. Das Kopieren von Gemälden, womit Krüger in München begonnen hatte, bildete ebenfalls später einen wichtigen Bestandteil seines Schaffens, größtenteils gerade auf Bestellung der von Lipharts in Dorpat. Ebenso übermittelt uns Krüger Eindrücke von seinen ersten Versuchen des Porträtierens. So finden sich in Krügers Briefen aus München schon jene Knotenpunkte, die in der sich an die Bildungsreise anschließenden Periode und während der Tätigkeit in Dorpat wichtig wurden.

Ein durchgängiges Thema in Krügers Briefen besteht darin, sich für eine Reise nach Italien vorzubereiten. (Krügers Reisebegleiter Karl Julius Senff, wie bereits erwähnt, reiste von München aus schon im Jahr 1830 weiter nach Italien, doch Krüger verschob die Italienreise auf die 


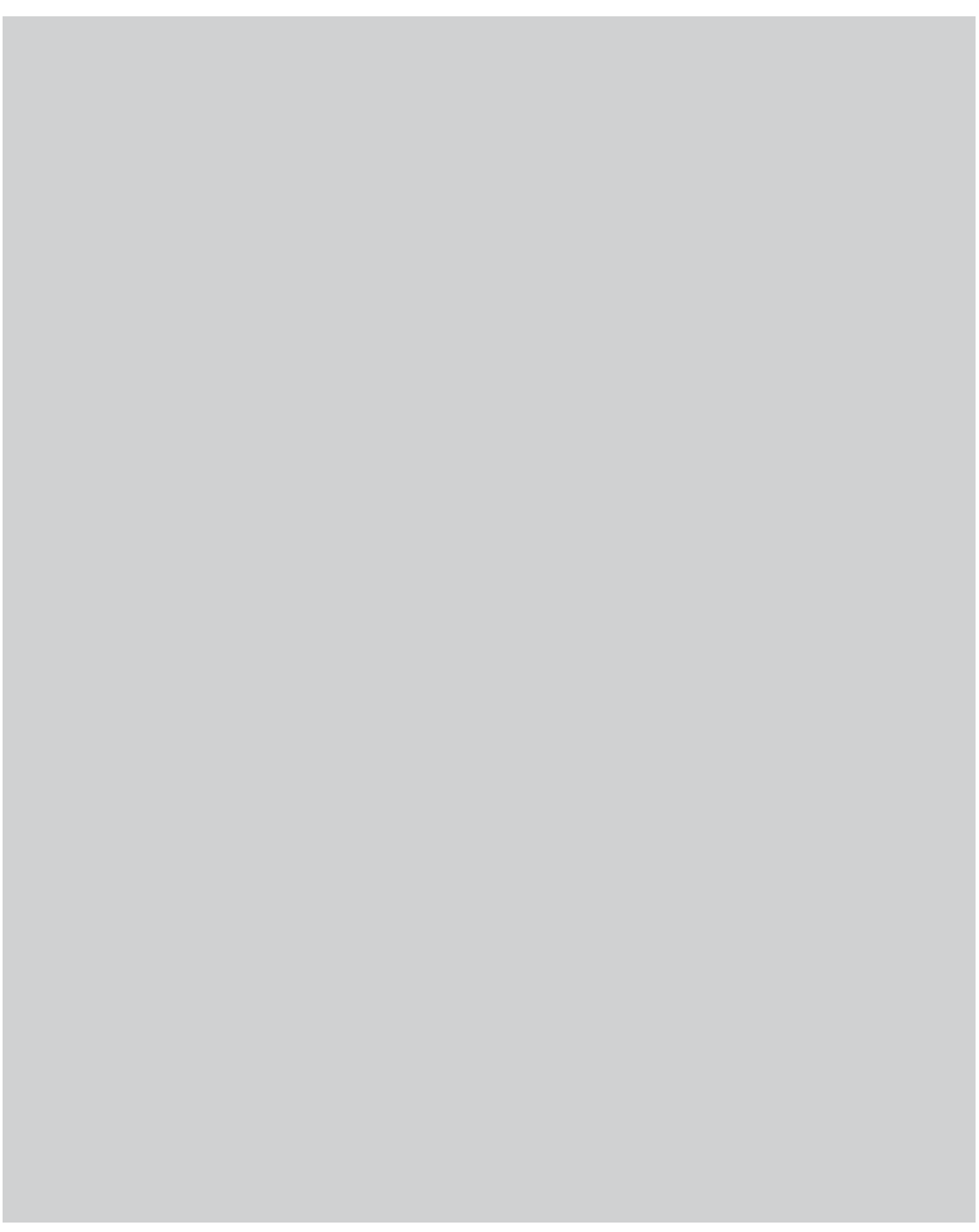

Abb. 5. Woldemar Krüger, Bildnis der Frau Rhomberg, Lithographie, 1832-1835. Kunstmuseum Tartu.

Zukunft.) In den Briefen lesen wir, dass Krüger einerseits die Reise nach Italien wünscht und erwartet, andererseits klingen Zweifel an, ob sich die Abwesenheit aus München, wo sich noch viel Nützliches angeeignet werden kann, nicht zu lang gestalten würde. Es scheint, als beabschtigte Krüger, dessen Kunststudium von einem fremden Geldbeutel abhing, zuerst durch das Erlernen praktischer künstlerischer Fertigkeiten seine Zukunft abzusichern, und als fürchtete er, dass einzig die Betrachtung von wertvoller Kunst wenig Nutzen abwerfe. Man denkt, dass es sich nicht allein um Zurückhaltung handelte bei der Akzeptierung einer Kunstreise nach Italien, deren Finanzierer erneut die Familie von Liphart gewesen wäre, mit deren Unterstützung Krüger ja auch nach München gereist war und dort verbleiben konnte. Krüger scheint praktisch veranlagt gewesen zu sein, was ihn im Gegensatz zu vielen anderen jungen Künstlern glauben ließ, dass Italiens Schönheit und seine Reize ihn zu weit weg von seiner notwendigen Arbeitsroutine führen könnte; war doch Italien noch im 19. Jahrhundert für einen Kunst interessierten praktisch Pflicht, sozusagen ein Wallfahrtsort, wohin viele zu reisen begehrten. Die Reise von den Alpen nach Süden, nach Rom oder in die Gegend von Neapel, verband viele damalige Künstler. Das Thema einer Italienreise verknüpft Krüger mit anderen deutschbaltischen Künstlern des 19 Jahrhunderts wie Friedrich Ludwig von Maydell, der Rom besuchte und sich in den zwanziger Jahren des 19. Jahrhunderts mit dem Kreis der dortigen Deutschrömer bekannt machte. Im Jahr 1833 und auch später reiste Carl Timoleon von Neff nach Italien. August Matthias Hagen verbrachte mit seiner Tochter Julie Hagen-Schwarz die erste Hälfte der fünfziger Jahre des 19. Jahrhunderts in Italien, nur um einzelne Beispiele anzuführen..$^{13}$ München war ein Zwischenhalt für die wegen der Kunst nach Italien Reisenden: Italiens Kunst und Architektur als Inspirationsquelle, besonders die antike Kunst und darunter der Reiz der Wandmalereien in Pompeji, herrschte in der Zeit von Ludwig I. in München in den dreißiger Jahren des 19. Jahrhunderts vor, als eine Reihe von Deutschrömern eine Beschäftigung gefunden hatten, unter vielen anderen Peter von Cornelius und Julius Schnorr von Carolsfeld. Wenn Krügers Lebenslauf aus einer späteren Perspektive betrachtet wird scheint es aber, dass seine nach langer Planung im Jahr 1834 erfolgte Italienreise auf sein Werk weniger Einfluss verfügte, als das in München Erlernte und Erfahrene.

13 Über die Reisen von Künstlern aus Estland nach Italien und ihre Motive sind Forschungen angestellt und Ausstellungen angefertigt worden. Siehe beispielsweise die von Tiina Abel betreute Ausstellung "Grand Tour. Künstler aus Estland in Italien" im Estnischen Kunstmuseum (Eesti Kunstimuuseum), 
Die Briefe aus München vermitteln uns auch einiges Privates über Krügers Leben in der Fremde. Der mit der finanziellen Unterstützung der von Lipharts ins Ausland gereiste Krüger möchte keine Zeit sinnlos verlieren, doch manchmal wird der Arbeitseifer durch ganz menschliche Dinge gestört: Mal ist ein langerwarteter Brief aus Dorpat nicht eingetroffen oder es stört der zu erwartende kalte und regnerische Winter oder es ist die Unbestimmtheit, wann die Reisepläne umgesetzt werden können. Zu Krügers alltäglichem Bekanntenkreis in München zählen anscheinend mehrere frühere Bekannte von Lipharts aus der Dorpater Zeit, über deren Aktivitäten er sich mit dem Freund auf dem Postweg austauscht, ebenso wie über seine Errungenschaften auf dem Gebiet der Kunst. In der Kommunikation zwischen den Freunden erscheint in den Reisejahren auch die Geldfrage. Zusammen mit Entschuldigungen informierte Krüger von Liphart über ausgebliebene oder verspätete Geldsendungen, welche die Alltagsabläufe beeinträchtigen. Das Mäzenatentum und der Aspekt der wirtschaftlichen Abhängigkeit beeinflussten in den Münchener Jahren die Beziehung zwischen den zwei Freunden wahrscheinlich stärker als später in Dorpat, als die Zeit der Studien vorbei war. Über die von Lipharts als Mäzene hat Dorothee M. Goeze ${ }^{14}$ geschrieben und tatsächlich ist dies ein Bereich, auf den eine stärkere Aufmerksamkeit gerichtet werden sollte und in dem noch einige bedeutungsvolle Fakten verborgen oder unbemerkt sein könnten. ${ }^{15}$

Vermittelt durch Krügers Briefe wird auch der damalige engere Freundeskreis des jungen Karl Eduard von Liphart deutlicher, als noch nicht Bekannte, die Kunsthistoriker waren, dominierten. Unter den Personen, denen Krüger durch von Liphart einen Gruß zukommen lässt, können viele Deutschbalten erkannt werden, die gleichzeitig mit ihnen an der Universität Dorpat studiert haben. ${ }^{16}$ Obwohl von Liphart in Dorpat offiziell keine Medizin studiert hatte, nahm er doch an den Vorlesungen teil und ein Kontakt mit Lehrkräften und Studenten der Universität war entstanden. Medizin studierte von Liphart in Königsberg und auch in Berlin, wohin Krüger die Mehrheit

14 Goeze, „Von der Pflicht, anregend, fördernd auf das geistige Leben seiner Mitbürger einzuwirken”. 15 So unterstützte von Liphart Anfang der sechziger Jahre des 19. Jahrhunderts auch den Grafike Eduard Ivanson bei seinem Kunststudium in Berlin (DSHI 110 Liphart II, 1-19, Bl. 9 ff).

Mehrere Namen konnten leider nicht identifiziert werden und bleiben somit ohne biografischen Kommentar.

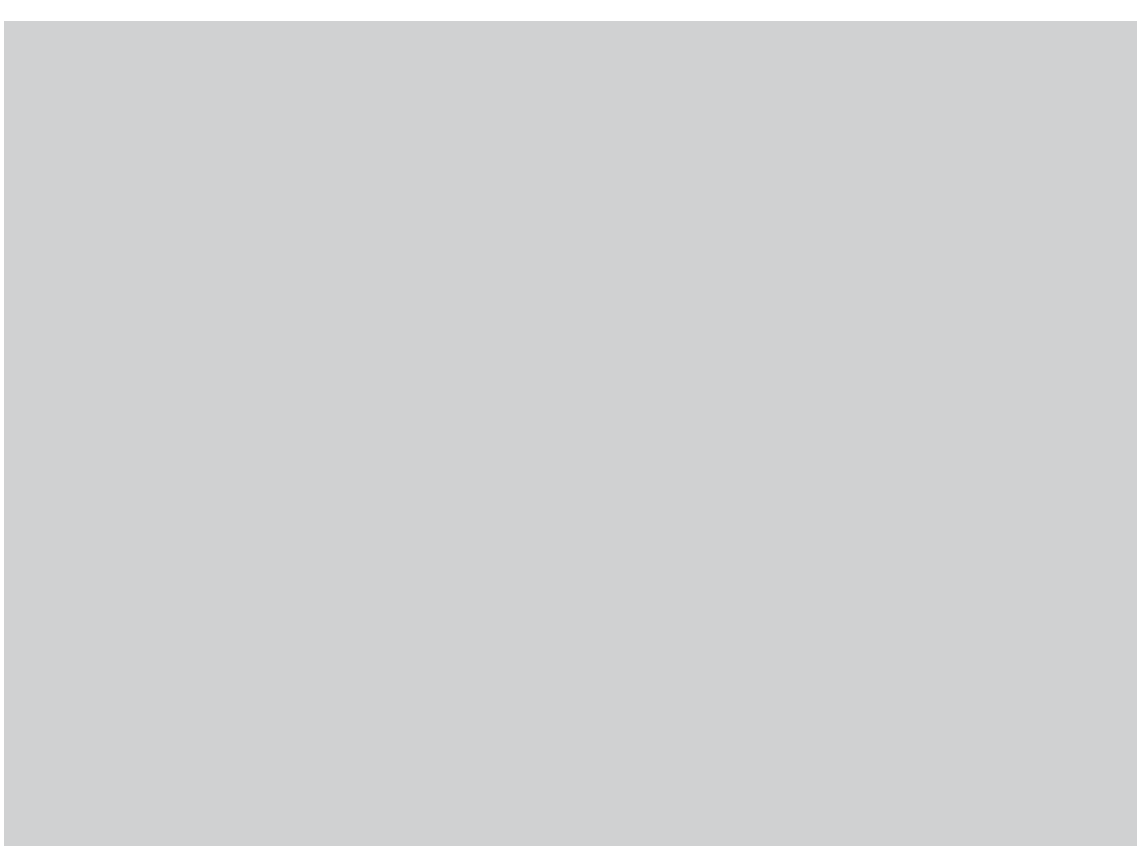

Abb. 6. Ferdinand Piloty (nach Peter Paul Rubens), Früchtenkrantz, Lithographie, 1837-1842. Von der Serie „Königl. Bayer. Pinakothek zu München und Gemälde-Gallerie zu Schleissheim /...।". Kunstmuseum der Universität Tartu.

der Briefe auch schickte. Im Nachhinein betrachtet kann bekräftig werden, dass für Karl Eduard von Liphart die im Jahr 1834 angetretene Italienreise ein entscheidendes Wegzeichen war, das den Blick des vielseitig begabten und mit zahlreichen Interessen ausgestatteten jungen Mannes endgültig in Richtung Kunstgeschichte lenkte. In Italien verbrachte von Liphart mehr Zeit als Krüger, er begegnete 1835 in Rom dem Kunsthistoriker Johann David Passavant und freundete sich mit ihm an, mit ihm zusammen besuchte er mit Raffael verbundene Orte. Auf die Italienreise folgte die zweite Berliner Phase Karl Eduard von Lipharts von 1836 bis 1839, als Woldemar Krüger bereits zurück in der Heimat war, doch diese Periode war schon durch ganz andere Personen gekennzeichnet. Dann nämlich setzten das intensive Kunstsammeln und natürlich Karl Eduard von Lipharts häufige Treffen mit Carl Friedrich von Rumohr, dem Direktor der Berliner Gemäldegalerie Gustav Friedrich Waagen und dem Kunstsammler 
Adolf Friedrich Schack ein. ${ }^{17}$ Erst im Jahr 1846 kehrte Karl Eduard von Liphart schließlich dauerhaft nach Dorpat zurück.

Die engere Bekanntschaft mit Karl Eduard von Liphart und ihre Einflüsse auf Krügers Leben lassen sich auch in den Jahren nach München verfolgen. Als er 1835 nach Dorpat zurückgekehrt war, heiratete Krüger und zum Wohnort wurde ein Haus in der Breiten Straße (Lai tänav) mitten in der Innenstadt, wo sich einige Häuser weiter auch das Stadthaus der von Lipharts befand, welches Karl Eduard von Liphart bei Aufenthalten in Dorpat als Wohnstätte nutzte. Im Jahr 1835 richtete Krüger auch eine lithografische Werkstatt ein, für die er bereits in München Pläne geschmiedet hatte. Doch bereits 1839 verkaufte sie Krüger weiter an Georg Friedrich Schlater, so erfüllten die Einkünfte, erzielt durch lithografische Drucke, wohl nicht die Erwartungen Krügers. In Dorpat begann Krüger auch als Zeichenlehrer zu arbeiten, diese Tätigkeit führte zu seiner Wahl als Lehrer der Zeichenschule der Universität im Jahr 1855. Eine Voraussetzung für den Arbeitsplatz als Zeichenlehrer an der Universität bestand im Status eines Mitglieds einer Akademie, dieser wurde schließlich 1858 durch die Kaiserliche Kunstakademie in St. Petersburg bestätigt. Karl Eduard von Liphart beriet und unterstützte Krüger später bei der Einrichtung einer Fotosammlung für die Zeichenschule der Universität. Die in München ihren Anfang genommene Anfertigung von Gemäldekopien beschäftigte Krüger auch in seiner Dorpater Periode. Auf seiner zweiten Auslandsreise 1847 in die Niederlande und nach Belgien kopierte Krüger auf Wunsch von Lipharts zahlreiche bekannte Kunstwerke aus den dortigen Sammlungen. Die Mittel der Wachsmalerei fanden bei von Lipharts Bestellung Anwendung bei der Dekorierung des Interieurs des Hauptgebäudes von Gut Ratshof in den vierziger Jahren des 19. Jahrhunderts ${ }^{18}$ und es ist provokativ zu denken, dass bei der Fertigstellung von Wandmalereien im pompejischen Stil für das Kunstmuseum der Universität 1868 eine gewisse Unterstützung durch Krügers in München erworbene Fähigkeiten der Wachsmalerei erfolgt sein könnte.

17 Waagen, Schack und den klassischen Archäologen Eduard Gerhardt traf von Liphart au den Abenden der sogenannten italienischen Gesellschaft, wo sie ihre Eindrücke und Gedanken zur italienischen Kunst und Kultur teilten. Alfred Friedrich von Schack, Ein halbes Jahrhundert. 18 Karl Krügers Manuskript „Erinnerungen an Woldemar Krüger”, EKLA F 169 M 19:1, 248-249.
Natürlich vermitteln ein Dutzend Briefe mit Kommentaren und einem knappen Geleitwort zusammen dennoch nur einen Ausschnitt aus der lebenslangen Freundschaft und der Beziehung zwischen einem Dorpater Künstler und einem Weltbürger und Kunstkenner. Eine Möglichkeit zu einem tieferen Einblick und einer umfangreicheren Diskussion böte die Kommentierung der sich in der Dokumentensammlung des HerderInstituts befindlichen, weiteren an Karl Eduard von Liphart gesandten Briefe. War doch der Bekanntenkreis des aus Dorpat stammenden Kunstsammlers bemerkenswert und aussagekräftig auch im breiteren Zusammenhang der westeuropäischen Kunst (beispielsweise der Briefwechsel mit Franz von Lenbach, Georg Treu und vielen anderen) Der Beziehung zwischen Krüger und von Liphart könnten wichtige Details hinzugefügt werden durch die gründliche Untersuchung von bisher unveröffentlichtem Quellenmaterial, das sich im Estnischen Literaturmuseum befindet. Ich denke in diesem Zusammenhang an das Manuskript Karl Krügers, auf das an dieser Stelle mehrfach verwiesen wurde, welches auch Abschriften von an Krüger gesandte Briefe enthält, darunter auch diejenigen Karl Eduard von Lipharts. ${ }^{19}$ Damit die Stimme eines Künstlers des 19. Jahrhunderts deutlicher zu uns dringt, sollten auch diese Materialien kommentiert und herausgegeben werden. 


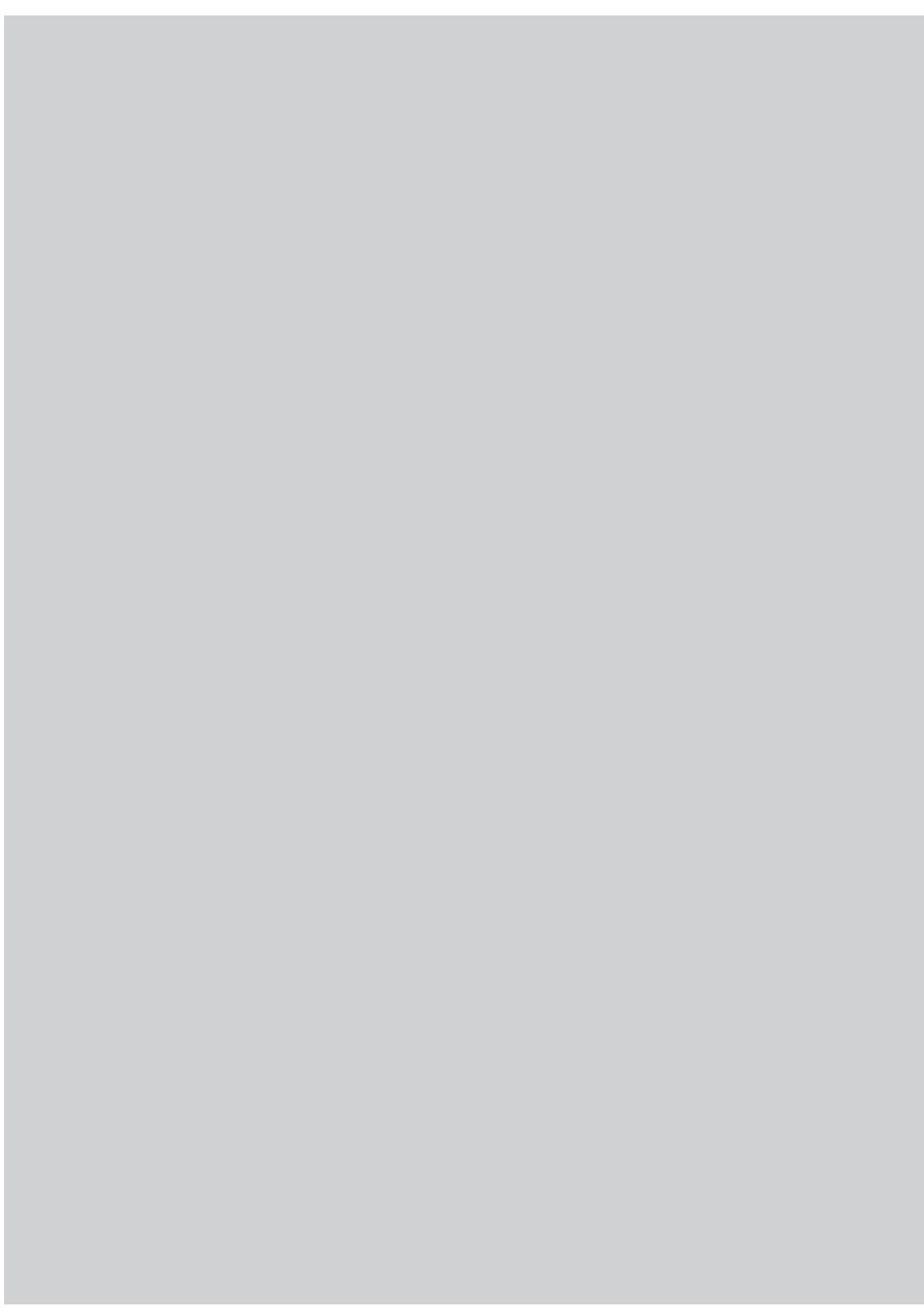

Abb. 7. Ernst Friedrich von Liphart, Bildnis Karl Eduard von Liphart, Feder, Tusche, 1888. Kunstmuseum der Universität Tartu.

\section{Lieber Liphart!}

Wie sehr ich mich gefreut habe, als ich Deinen Brief erhielt, kannst Du leicht denken, wenn ich sage, daß ich schon seit Monaten ${ }^{20}$ auf eine Nachricht von Dir mit großer Ungedult gewartet habe.

$\mathrm{Daß}$ Du nun meiner gedacht hast, dafür empfange hiermit meinen herzlichsten Dank. Mir ist es bis jetzt zu meiner großen Zufriedenheit gut gegangen, was ich nächst Gott nur Dir zu danken habe, denn Deine Güte hat mich in den Stand gesetzt, so viel Nützliches zu lernen.

Deiner Aufforderung mich mit dem Steindruck bekannt zu machen bin ich gefolgt, und habe schon im Frühlinge damit angefangen..$^{21}$ Beiliegendes kleines Blättchen mag bezeugen, was ich bis jetzt leisten kann. Ich habe es nach einem geätzten Blatt von Kobell gezeichnet ${ }^{22}$, und dieses darum gewählt, weil so starke Dunkelheiten im Druck schwieriger zu behandeln sind. Auch habe ich den Stein selber geätzt und hernach Druck gemacht. ${ }^{23}$ Dieses ist die dritte Probe, die ich gemacht habe. Die Kreidemanier ${ }^{24}$ ist die schwierigste von allen, und will von a bis z vom Zeichnen bis zum Drucken mit vieler Aufmerksamkeit und Sorgfalt behandelt seyn. Ich habe das Glück gehabt bei einem der Sache sehr kundigen Mann in die Lehre gekommen zu seyn. Jetzt wünschte

20 Krüger erreichte München im Herbst 1830. Im Frühling desselben Jahres hatte er Dorpat verlassen, er machte in Riga und Berlin Zwischenstation und erreichte dann Dresden. Doch weil es schwierig war, sich an der dortigen Kunstakademie zu immatrikulieren, entschied er sich, nach München weiterzureisen. München blieb der hauptsächliche Aufenthaltsort Krügers während seine

1 Im Jahr 1796 erfand der Bayer Alois Senefelder die Methode des Steindrucks, also die Lithografie dabei verwendete er das Prinzip der Abstoßung von Wasser und Fett sowie glatt geschliffenen Kalkstein 1799 eröffnete er in München seine lithografische Druckerei, 1818 gab er ein technisches Handbuch heraus. München war in den ersten Jahrzehnten des 19. Jahrhunderts ein wichtiges Zentrum des lithografischen Drucks, wo mehrere Serien von Reproduktionen der Arbeiten der Bayrischen Königlichen Kunstsammlung herausgegeben wurden.

2 Ferdinand Kobell (1744-1799) war deutscher Maler und Grafiker. Er war in Bayern aktiv, von $\mathrm{hm}$ sind fast 300 Radierungen bekannt, die, vermittelt durch eine Ausgabe von 1809 von Frauenholz auch Kruger gekannt haben könnte. Ferdinand Kobell trug wesentlich zum Fortschritt der Grafik in Deutschland bei, dabei gestaltete er viele Landschaften im Stil von Nicholas Berchem. Es erscheint al möglich, dass einer der ersten Versuche Krügers auf dem Gebiet der Lithografie in der Sammlung des Tartuer Kunstmuseums (Tartu Kunstimulum, TKM TR mit Kobells Landschafte

23 Zur Festigung der Zeichnung auf dem lithografischen Kalkstein musste diese leicht eingeätzt werden. Der Künstler konnte sich auch nur auf das Zeichnen auf den Stein konzentrieren und da Atzen und andere derartige Vorbereitungen fur das Drucken übernahm dann ein anderer Meister. 24 In der lithografischen Technik gab es verschiedene Methoden, um die Abbildung auf den Stein zu übertragen: ob mit lithografischer Tusche, mit der Feder und dem Pinsel, mit fettiger lithografischer Kreide oder mit einem speziellen Stift. Entsprechend bestand das Ergebnis in einer Druckflache, die
einer Feder- oder Kreidezeichnung oder einer Bemalung ähnelte. 
ich mir bald Gelegenheit zu erhalten, das Gelernte anwenden zu können, und da denke ich, könnte sie wohl am Besten bei uns zu Hause gefunden werden. In Ansehung der Kalksteine erlaube ich mir an Dich, als einem Mineralogen ${ }^{25}$ eine Frage zu wenden. Könntest Du mir vielleicht Aufschluß ertheilen, von welcher Beschaffenheit die in Liev- und Esthland gefundenen Kalksteine sind? Es wäre doch ein wesentlicher Vortheil, wenn der Stein sich zur Lithographie tauglich zeigte. ${ }^{26}$ Das Haupterforderniß ist eine durchgängig gleiche und feine feste Masse. Ich erinnere mich einmal gehört zu haben man habe in Petersburg Versuche mit Steinen aus Esthland gemacht, sie aber zu locker gefunden, um sie zu feinern Arbeiten gebrauchen zu können. Es fragt sich aber, ob jene Versuche mit gehöriger Sorgfalt angestellt worden sind.

Ferner habe ich im Laufe dieses Sommers auf der hiesigen GemäldeGallerie ein großes Bild nach Rubens gemalt ${ }^{27}$; zu Hause habe ich Landschaften nach der Natur in Deckfarben ausgeführt, von denen mir mehre wohl gelungen sind, und noch nebenbei gezeichnet.

So ist mir der Sommer so schnell vorübergegangen, daß ich mit Schrecken durch die kühle Witterung an den herannahenden Winter erinnert werde. Vor einigen Tagen kam ich von einem Ausfluge ins bayerische Hochgebirge bis an die Tyroler Grenze hin, zurück, hatte aber leider nur anderthalb Tage gutes Wetter, und da wo ich es gerade recht gebraucht hatte, hat es heftig geregnet, und das ganze Gebirge war mit Schnee bedeckt. Diese großen Steinmassen, die alle Aussicht verschließen, haben auf mich einen eigenen Eindruck gemacht. Ich kann sie in Ansehung der Formen, besonders in der Nähe gar nicht schön nennen, aber großartig ist ihr Anblick, das ist wahr. Nur Schade, daß besonders in diesem Sommer das Wetter so wenig anhaltend gut gewesen ist. Wurde es einmal warm, so war die Hitze unerträglich, sie währte aber nicht lange denn ihr folgte gar bald ein Gewitter, das die Luft empfindlich

25 Hier weist Krüger offensichtlich auf Karl Eduard von Lipharts vielseitige Interessen und Talente hin, die von den Naturwissenschaften über die Medizin bis hin zu den schönen Künsten reichten. 26 Für die lithografische Technik eignet sich am besten der sogenannte Solnhofener Kalkstein, de gleichnamige Fundort liegt in der Nähe von München. Der estnische Dolomit ist für den Steindruck zu uneinheitlich zusammengesetzt.

27 Laut den Angaben von Karl Krüger kopierte Woldemar Krüger im Münchener Sommer den "Früchtekranz” (117x203 cm, Alte Pinakothek) von Peter Paul Rubens, dies könnte möglicherweise das im Brief erwähnte Bild sein. Das Gebäude der Alten Pinakothek wurde 1836 fertiggestellt, doch die königlich bayrischen Sammlungen waren auch schon früher für den Besuch geöffnet und Krüge 19. Jahrhunderts die Kunstsammlungen der Öffentlichkeit). abkühlte. Das Rauhe des hiesigen Klimas ist für mich weit empfindlicher, als bei uns die stärkere Kälte.

Es thut mir unendlich leid, daß aus Deinem schönen Plan, der recht nach meinem Sinn gewesen wäre, nichts geworden ist. Ich glaubte Dich schon lange in Berlin, und hätte viel eher aus Heidelberg, als aus Königsberg einen Brief erwartet, und aufrichtig gestanden, wärest Du da gewesen so hätte ich mich gewiß bald zu Dir aufgemacht. ${ }^{28}$ Denn unter meinen [teilweise zerstört, evtl.: Wünschen ist der erste] Dich recht bald zu sehen, denn ich hätte doch Einiges, worüber ich mich mit Dir mündlich gern besprechen möchte. Wie lange bleibst Du noch in Königsberg?

Wohin geht es von da? Ich hoffe, Du wirst die Güte haben mich zu seiner Zeit davon zu benachrichtigen. Am Besten ist es, Du kommst recht bald aus dem Norden in eine südlichere Gegend.

Im nächsten Monat giebt es hier was zu sehen, es wird nemlich die Kunstausstellung eröffnet..$^{29}$ Ich bin sehr begierig darauf, denn hier findet sie nur alle drei Jahre statt. Die Nachricht vom Tode Julius Senffs ${ }^{30}$ hat mich in der That sehr betrübt, da ich jetzt bestimmt weiß, daß er nicht mehr ist, denn erfahren hatte ich es schon früher, aber nicht so gewiß, und hoffte bis jetzt, daß es sich nicht bestätigen werde. Nimmer hätte ich es gedacht, als wir uns hier trennten, ihn in diesem Leben nicht mehr zu sehen.

Was die altteutsche Schule anbelangt, so bin ich ihr wenig befreundet. ${ }^{31}$ Ich habe ja die [...] Sammlung, die wohl die ausgesuchtesten Gemälde der altteutschen Schule enthält, und auch die andern Bilder dieser Schule hier gesehen, allein das Alles, was ihre Verehrer an ihnen so sehr preisen, hat mir in dem hohen Grade nicht einleuchten wollen. Es ist wahr, man kann ihnen manches Verdienst nicht absprechen, allein ihre Verdienste, ohne

28 Karl Eduard von Liphart studierte Anfang der dreißiger Jahre des 19. Jahrhunderts Medizin 28 Karl Eduard von Liphart studierte
zuerst in Königsberg und dann in Berlin.

29 Die Ausstellung der Münchener Kunstakademie wurde am 12. Oktober 1832 eröffnet. Vertreten 29 Die Ausstellung der Münchener Kunstakademie wurde am 12 . Oktober 1832 eröffnet. Vertret
waren unterschiedliche Kunstgenres und Werke von deutschen und ausländischen Künstlern.

waren unterschiedliche Kunstgenres und Werke von deutschen und aussändischen Künstlern.
30 Karl Julius Senff (1804-1832), der Sohn des Lehrers der Zeichenschule der Universität Dorpat Karl August Senff, studierte an der Universität Dorpat, versuchte sich auch an Grafiken, erhielt 1829 in kaiserliches Reisestipendium, mit dessen Unterstützung er in Prag und Wien Architektur studierte reiste von dort mit Krüger nach München. Er verstarb 1832 auf einer Italienreise in Mailand an eine unerwarteten Krankheit.

31 Unter der sogenannten altdeutschen Schule verstand man zur Zeit Krügers die deutsche Malere des 15. und 16. Jahrhunderts. Ludwig I. kaufte 1827 die Kunstsammlung der Boisséeres und 1828 die Oettingen-Wallerstein-Sammlung, die beide gerade wegen ihrer Prominenz der sogenannten altdeutschen Kunst ins Auge stachen. In der heutigen Kunstwissenschaft wird für diese Periode auch
der Begriff deutsche Spätgotik verwendet. 
ihre Mängel haben ja die Meister andrer Schulen in ihren Bildern vereinigt. Ich will mich über diesen Punkt nicht weiter auslassen denn es wäre eine harte Probe für Deine Gedult, da ich ohnedieß genug geschwetzt habe. Vor allen Dingen wünsche ich Dir dauernde feste Gesundheit.

Das im Mai fällige Tertial habe ich hier richtig am 2ten Juli neuen Styls erhalten, wofür ich nochmals sehr danke. Auf jeden Fall hoffe ich nicht mehr so lange auf eine Nachricht von Dir warten zu müssen, denn ich kann Dir nicht sagen, wie peinlich mir es ist, so gleichsam wie in einem Sack zu leben. Ich wollte der Winter wäre schon vorbei, und es begönne wieder der Frühling. Allein wie Gott will, so muß es geschehen. Nun lebe recht wohl, bis wir uns sehen. Diesen Augenblick erwartet mit Freude Dein für immer mit der größten Dankbarkeit

Einen herzlichen Gruß an Senff. ${ }^{32}$

München am 20sten Sept. 1832. verpflichteter Woldemar Krüger

\section{Lieber Liphart!}

Vor allen Dingen muß ich um Nachsicht bitten, daß ich durch meine Ungeduld getrieben, Dich so schnell wieder mit einem Briefe belästige.

Ich hoffe, Du wirst meinen Wunsch im letzten Briefe, in Hinsicht der Lithographie, nemlich eine selbst anzulegen errathen haben, und dieses möchte ich, wenn ich einmal zurück gekehrt bin, gern in Dorpat, daher auch die Erkundigung der Kalksteine wegen. Ich bin nun in einiger Unruhe, weil ich in Erfahrung gebracht, daß andre ebenfalls gleiche Absichten hegen, und fürchte sie möchten mir zuvorkommen. ${ }^{33}$

Meine Bitte ergeht daher an Dich, wenn es möglich ist, einige Augenblicke abzumüssigen, mir darüber Deine Meinung vorläufig mitzutheilen, da Du durch ausgebreitete Bekanntschaft im Stande bist, die

32 Wahrscheinlich sandte Krüger über von Liphart Grüße nach Dorpat an Karl August Senff. Karl August Senff (1770-1838), deutschbaltischer Künstler, war der erste Leiter und Lehrer der Zeichenschule der Universität Dorpat (1803-1838), bei Senff in der Zeichenschule wurde auch Krüger ausgebildet. 33 Krügers Befurchtungen, dass seine Kollegen in Dorpat ebenfalls an eine lithografische Druckere dachten, hatten ihre Berechtigung. Der Künstler Georg Friedrich Schlater eroffnete in Dorpat seine
lithografische Druckerei bereits im Jahr 1832.
Sache besser zu beurtheilen, als ich. Überdies hoffe ich, so glücklich zu seyn, im nächsten Frühlinge, Dich persönlich zu sehen u zu sprechen.

Vor einigen Wochen traf ich hier zufällig Gregor Helmersen ${ }^{34} \mathrm{u}$ $H_{\text {Hoffmann }}{ }^{35}$, die aus der Schweiz kamen. Letzterer wird auf seiner Rückreise über Königsberg kommen. Die Ausstellung der Kunstwerke ist hier schon angegangen. Es sind an Gemälden recht schöne da. Beschreibungen solcher Gegenstände sind mir langweilig, man muß sie sehen Der Erfüllung meiner Bitte sehe ich bald entgegen, und verbleibe mit Achtung und Dankbarkeit

Dein stets ergebener Woldemar Krüger München am 15ten Octobr. 1832

Meine Adresse: Neuhausergasse. 1099. 3 Stiegen $^{36}$

\section{Liebster Liphart!}

Vielen, vielen Dank für den Brief, der mir so angenehme Nachrichten gebracht hat, denn Dich jetzt in Berlin, und daher um ein Bedeutendes näher zu wissen, ist für mich um so erfreulicher, da ich Dich noch immer in Königsberg glaubte. Ich kann nicht läugnen, daß ich einer Antwort früher entgegen gesehen habe, allein ich tröstete mich mit dem Gedanken, daß Du wohl vorher über die Steine irgend eine nähere Erkundigung einziehen wolltest, und daher auch die Verzögerung. Daß mein Plan

34 Gregor von Helmersen (1803-1885), deutschbaltischer Geologe, studierte 1821-1825 an der Universität Dorpat, bildete sich in den dreißiger Jahren des 19. Jahrhunderts an deutschen Universitäten weiter, war spater Professor des St. Petersburger Bergbauinstituts (anfangs Instituts des Ingenieurskorp Sur Bergbau) sowie dessen Direktor (1865-1872), nahm an etwa 30 Forschungsreisen in Russland und
Skandinavien teil. Skandinavien teil.

35 Ernst Reinhold Hoffmann (1801-1871), deutschbaltischer Geologe, studierte an der Università Dorpat Medizin und Geologie, nahm an Otto von Kotzebues Reise um die Welt teil, 1830-1832 bildete er sich in Deutschland und Osterreich fort. Er unternahm mit von Helmersen mehrere Forschungsreisen unter anderem begleiteten sie 1829 den Dorpat besuchenden Alexander von Humboldt auf seine 36 Krügers Wo

36 Krügers Wohnsitz war eine Wohnung an einer der Hauptstraßen in der Münchener Altstadt. Die Neuhauser Straße, heutzutage mit vielen Geschäften eine etwa 300 m lange Fußgängerzone, stellt
eine wichtige Verbindung zwischen dem Münchener Rathausplatz und dem Karlsplatz dar. 
Deine vorläufige Zustimmung hat, ist mir sehr lieb. Was die Kalksteine anlangt, so erwartete ich schon nichts Günstigeres zu erfahren, als ich schon wußte, doch hoffe ich, dieses Hinderniß wird nicht so schwer zu besiegen seyn. Sennefelders ${ }^{37}$ neue erfundene Stein[pappe?] ist mir woh bekannt, denn ich kenne die Verhältnisse und Bestandtheile derselben, allein sie ist nicht das, was Sennefelder erwartete. ${ }^{38}$ Zum Überdruck von Schriften und dergleichen Arbeiten läßt sie sich wohl gebrauchen, allein bei der Kreidemanier vertritt sie den Stein lange nicht, denn sie läßt ihre Oberfläche nicht so schleifen und zum Korn zurichten, wie der Stein. So viel mir bekannt ist, brauchen auch alle, Engländer, Franzosen, so wie andere Nationen den bayrischen Kalkstein aus Sohlenhofen. ${ }^{39}$ Der Stein an $\mathrm{u}$ für sich kostet an Ort und Stelle gar nicht viel, wenn man bedenkt, daß er fünfzig, ja hundert mal von neuem gebraucht werden kann. Es ist nur der Transport, doch sagte mir ein Steinlieferant aus Sohlenhofen, daß die Kosten des Transports nach Paris beinahe mehr beträgen, als die von Sohlenhofen bis Petersburg.

Daß ich mich vor der Ausführung meines Planes noch erst mehr in der Welt umsehen soll, ist wohl auch mein eigener Wunsch, denn ich gestehe es offen, daß ich München recht gern verlassen möchte, und je eher, je lieber. Wohin? kann ich nicht bestimmen und stelle dieses Dir anheim. Nur wollte ich bitten, im Fall Du damit zufrieden bist, mir Deine Meinung darüber wissen zu lassen, damit ich weiß, wie ich es mit meiner Wohnung hier zu halten habe. Überdieß hoffe ich wohl vorher zu erfahren, wann ich das Glück haben werde, Dich zu sehen. Ich freue mich schon im Voraus auf den Sommer, denn den Aufenthalt hier bin ich satt.

Das September-Tertial ist mir bis jetzt noch nicht ausgezahlt worden; die Verzögerung kann ich mir nun leicht erklären, und bedaure Asmuss ${ }^{40}$ von Herzen, einen so großen Verlust erlitten zu haben, und verzeihe ihm

37 Alois Senefelder (1771-1834), Erfinder des lithografischen Drucks, Verleger, beschäftigte sich sein Leben lang mit der Verbesserung der lithografischen Technik und ihrer Erneuerung. Siehe auch Anmerkung 21 .

Anmerkung 21. 38 Bereits im 19. Jahrhundert wurde neben Kalkstein nathe
als Druckplatten für die lithografische Technik eigneten. 39 Solnhofen (oder Sohlenhof) befindet sich auf halber Strecke zwischen Nürnberg und München und
als Druckplaten ist bekannt als ein Fundort von besonderem Kalkstein. Der Solnhofener Kalkstein ist sehr feinkörnig stark und widerstandsfähig, von Natur aus mit einer sehr dichten und einheitlichen Oberfläche und
deshalb bestens für den lithografischen Druck geeignet.

40 Wahrscheinlich Johann Martin Asmuss (1784-1844), deutschbaltischer Pädagoge, Schriftstelle Kassensekretärs arbeitete. Er könnte den von Lipharts in finanziellen Angelegenheiten geholfen haben. gern, daß er in einem solchen Falle an mich nicht gedacht hat. Vielleicht hat er es schon besorgt, und es wird bald anlangen.

Lebe wohl und gesund und gedenke bisweilen

Deines ganz ergebenen

Woldemar Krüger

München am 8ten Januar 1833.

Bester Freund!

Wie soll ich Dir danken für Deine so überaus große Güte, mit der ich von Dir überhäuft werde. Den Vorschlag nach Italien zu gehen habe ich hin und her bedacht, und da ich selbst nicht geringe Lust dazu hätte, so nehme ich Dein gütiges Anerbieten mit dem größten Danke an. Nur befürcht ich, Du werdest über einiges mit mir nicht einverstanden seyn Ich hätte nemlich den Wunsch wohl dahin zu reisen, aber nur um das schöne Land mit seinen herrlichen Kunstschätzen zu sehen, mich aber daselbst nur so lange aufzuhalten, als nöthig ist. Alles mit gehöriger Muße kennen zu lernen, also noch gegen Ende dieses Jahres zurückkehren zu dürfen. ${ }^{41}$ Und dieses aus dem Grund, weil ich mich jetzt fast ausschließlich für die Lithographie entschieden habe und meine, ein längerer Aufenthalt daselbst hätte gerade für diesen Theil der Kunst keinen wesentlichen Vortheil. ${ }^{42}$ Daß hier nur von dem [Mus-?] [ischen?] die Rede seyn kann versteht sich von selbst, denn das unterliegt nun keinem Zweifel, daß außerdem eine Reise dahin, immer sehr nützlich in Hinsicht der Kunst ist. Da nun auch der günstigste Zeitpunkt zur Reise spätestens im Mai wäre, so hätte ich gebeten, mich darüber früher zu benachrichtigen, ob ich Dich vor dieser Zeit irgendwo sprechen kann, denn früher möcht ich mich nicht von hier, und zwar noch weiter entfernen, bevor ich Dich gesehen, denn ich habe noch mehres, was

41 Als er die Italienreise schließlich durchführen konnte, verbrachte Krüger dort weniger als ein Jahr und kehrte früher nach München zurück als von Liphart.

42 Krüger bestellte sich aus München auch eine lithografische Druckerpresse, welche er nach Dorpat mitnahm. 
ich unmöglich schriftlich so sagen kann und daher für eine mündliche Mittheilung aufschiebe. Es wäre auch der Wohnung wegen die man hier immer einen Monat früher, als man auszieht, kündigen muß. Übrigens füge ich mich ganz Deinem Willen, erwarte Deine nähere Bestimmung darüber und verbleibe Deiner außerordentlichen Güte gegen mich stets eingedenk Dein ganz ergebener

Woldemar Krüger München am 26 Febr. 1833.

\author{
Liebster Liphart!
}

Ich beeile mich Deinen so eben erhaltenen Brief sogleich zu beantworten, und pflichtgemäß zu melden, daß ich am 8ten Mai a. [...] 1000 Rbl. ${ }^{43}$ ausgezahlt erhalten habe wobei ich zugleich für Deine unbegrenzte Güte, der ich allein Alles zu verdanken habe, meinen unendlichen Dank abstatte. Wenn ich es nur mit so wenigen Worten thue, so bitte ich ja nicht zu glauben, als ob ich die Größe der Gabe und den Werth des Gebers nicht zu schätzen wüßte, sondern daß ich es viel besser empfinde, als es mit Worten zu sagen, im Stande bin. Viel lieber hätte auch meinen Dank mündlich abstatten mögen, und hoffte mit großer Freude drauf; der Wunsch ist mir nun leider nicht gewährt worden, was mir in vieler Hinsicht sehr betrübend ist. Ich will denn also meine Reise nach Italien getrost antreten, und so bald, als möglich aufbrechen. ${ }^{44} \mathrm{Zu}$ meinem Leidwesen vermisse ich auch in dem Briefe einen Aufschluss über meine früher geschehene Anfrage, ob ich nemlich länger daselbst verweilen, oder wie ich es wünschte im Herbste zurückkehren dürfte. Ferner wünschte ich noch zu wissen, wohin ich denn bisweilen Nachrichten zu geben hätte, ob immer nach Berlin, oder sonst irgendwo? Nur über dieses beides bitte ich Auskunft, was mit einigen wenigen Zeilen geschehen ist, und zwar ehe ich mich von hier entferne. Bis in 14 Tagen von

43 Zu dieser Zeit wurde der Rubel entweder als Silber- oder als Papiergeld verwendet, wobei letzteres weniger wert war, ein Silberrubel kostete etwa 3,6 Papierrubel. Doch 1.000 Papierrubel stellten imme noch eine große Summe dar, je nach Aufenthaltsort in Europa entsprach sie der Kaufkraft von 4.00 bis 10.000 heutigen Euro.

4 Be $n$ nterweise erfolgte die Italienreise dennoch erst im Frühjahr 1834, wie es sich aus den folgenden Briefen ergibt. heute wünschte ich abzureisen ${ }^{45}$, und hoffe von Deiner Güte, bis dahin meinen Wunsch erfüllt zu sehen. Es würde mich sehr schmerzen, ungewiß abreisen zu müssen. Ich versichere nochmals, daß ich nie aufhören werde, Deiner Güte zu gedenken, und bleibe mit der größten Achtung und Dankbarkeit Dein

Woldemar Krüger. München am 20/8 Mai 1833. Meine Adresse: Neuhausergasse. No. 113 Stiegen
Liebster Liphart!

ich hoffe Du bist glücklich in Berlin angelangt, und hast auch schon die Beschwerden der Reise vergessen. ${ }^{46}$ Ich aber habe gar keine Ruhe, und sehne mich herzlich nur lieber heute als morgen von hier fortzukommen, denn den Zweck meines Aufenthalts habe ich nur halb erlangt, wenn ich gleich nicht aufgegeben habe mehr zu erfahren allein jetzt wird es nicht gehen. Was die Freskomalerei anlangt, so ist mir deren Behandlungsart gut mitgetheilt, nur mit der Enkaustischen ${ }^{47}$ hat es seine Schwierigkeit. Ich habe schon mit Hoffmann ${ }^{48}$ mehre Male gesprochen. Jetzt ist es nicht mehr sein Eigenthum, er hat es, wenn ich so sagen kann

\begin{abstract}
45 Bezüglich der Reise 1833 sind die Angaben etwas verwirrend. Von Mai bis Dezember fehlt auch der entsprechende Schriftverkehr. Es scheint, dass Krüger und von Liphart in der Zeit zusammen reisten, wahrscheinlich in Deutschland an den Rhein, in den Biografien der beiden finden sich Hinweise auf eine entsprechende Reise. Auf jeden Fall fand das von Kruger lang erwartete Treffen $\mathrm{mit}$ von Liphart im Jahr 1833 statt und Krüger konnte von Liphart seinen Dank für dessen Unterstützung
auch direkt aussprechen. auch direkt aussprechen.

46 Im Oktober 1833 war von Liphart noch in München (siehe DSHI 110 Liphart 4, Bl. 110) und reiste von dort nach Berlin zurück.

47 Bei der Enkaustik oder Wachsmalerei werden auf die Wandfläche mit heißem Wachs vermischte Pigmente aufgetragen. Die Technik wurde in der Antike beispielsweise bei den Wandmalereien in Pompeji angewandt sowie ebenfalls beim Kopieren des Pompeji-Stils im 19. Jahrhundert. Bei den Innenbemalungen im Gut Ratshof in den vierziger Jahren des 19. Jahrhunderts (EKLA F 169 M 19:1,
Bl. 248-249) könnte Krüger die in München erlernte Technik angewandt haben. 48 Der Vorname Hoffmanns konnte nicht ermittelt werden.
\end{abstract}


dem Könige verkauft, oder vielmehr Klenze ${ }^{49}$ mitgetheilt, und ist dafür bei dem Königsbau ${ }^{50}$ angestellt, und darf nun nichts mehr Fremden eröffnen. Einem Franzosen, der deshalb hierher gekommen war, um es zu erfahren hat Klenze sein Gesuch abgeschlagen.

Fürs erste bin ich zufrieden, daß ich nur weiß, woraus das Bindemittel der Farben besteht. Mit Hoffmann mag ich aufrichtig gesagt, auch nicht recht viel zu schaffen haben, er spricht immer lieber von Dingen, die er gar nicht versteht, und macht, ich weiß nicht was für große Pläne, mit denen ich nicht sehr einverstanden bin. Was mich aber meisten unmuthig und mit mir selbst unzufrieden macht, ist, daß ich gar keine Stunden, keine Hülfsmittel zu eigenen Arbeiten habe; ich müsste mich denn immer nur auf Nachahmen beschränken, und das ist es, was mich forttreibt. ${ }^{51}$ Dazu kommen die kurzen Tage, das nasse, trübe Wetter hinzu, die Zeit vergeht, ohne daß ich etwas Erhebliches hervorgehen sehe. Ich tröste mich damit, daß es Ende dieses Monats oder im Anfange des nächsten fortgeht. Swerdjö $e^{52} \mathrm{u}$ Schölern geht es nicht besser, wie mir.

Zürne mit nicht, liebster Liphart, daß ich so seltsam und unbeständig erscheine, ich wollte gern, ich wäre anders.

Von Madame wäre wieder gar vieles zu erzählen, besonders lustig war es, als sie sich vor einigen Tagen schwanger glaubte. Ihre Freude hättest Du sehen sollen. Jetzt ist es aber schon wieder vorbei, denn als ich heute hinkomme, hieß es: der Kleine, denn ein Knabe mußte es nun schon sein, sei schon abgefahren und Alles war bloßer Wind gewesen.

49 Leo von Klenze (1784-1864), deutscher Architekt, war der Hofarchitekt Ludwigs I., 1826-1842 wurde der Anbau der Münchener Residenz der Wittelsbacher fertiggestellt (der sogenannte Königsbau der Festsaalbau und die Allerheiligen-Hofkirche), wo von Klenze auch die Innengestaltung plante, darunter Wandmalereien. Klenze hielt die Enkaustik fur eine ideale Technik fur Wandmalereien un Weltkrieg zwar stark beschädigt, Rech wurde er anschließend zum größten Teil wiederhergestellt. Wethrieg zwar stark beschadigt, doch wurde er anschließend zum goBten Terl wiederhergestellt. Die zweite bedeutende Arbeit von Klenze war in diesem Zeitraum das Gebäude der Alten Pinakothe (1826-1836).

50 Als Vorbild des äußeren Erscheinungsbilds des Königsbaus nahm Leo von Klenze Florentiner Renaissancepalazzos (Palazzo Pitti, Palazzo Ruccellai). Im Königsbau wurden auch die Wandmalereien von Julius Schnorr von Carolsfeld nach Motiven des Nibelungenlieds angefertigt (die sogenannte Nibelungensäle).

51 Krüger ist unruhig, dass er sich einzig mit dem Kopieren beschäftigen soll und dass für sein eigenes Werk Zeit und Ratschläge nicht ausreichen.

Moritz Adolph Sverdsjoe (1806-1848), studierte an der Universität Dorpat Medizin (Dissertation 1830).
Swerdsjöe, der einen Brief mit einlegt, wird ausführlicher berichten. Ist für mich kein Brief da? Grüße Paul ${ }^{53}$, Erdmann ${ }^{54}$, Innosemzeff55, Schmidt und andre herzlich von mir. Lebe wohl, recht wohl, liebster Liphart, und denke bisweilen mit Liebe

Deinen treuen Woldemar Krüger München am 3ten Decbr. 1833

\section{Liebster Liphart!}

Werde nicht ungehalten, daß ich Dich mit Schreiben so sehr bestürme; mich treibt jetzt eine besondere Ungeduld dazu, und erst, wenn ich diesen Brief auf der Post weiß, bin ich zufrieden. Zuerst muß ich Dir melden, daß die Reise-Gesellschaft auf fünf Personen angewachsen ist ${ }^{56}$; denn Berg u Schiemann haben sich uns angeschlossen. Vor allen treibt Schiemann zum schnellen Aufbrechen, und den Tag der Abreise haben wir denn auch auf den 29ten Dcbr festgesetzt. Nun bitte ich Dich, theurer Liphart! wenn es möglich wäre, mir vorher einiges Geld zu übersenden, da ich mit den nicht vollen hundert und fünfzig Gulden, die ich nach Abzug aller zu machenden Zahlungen hier übrig behalte, ungern die Reise antreten möchte, am allerwenigsten aber in die Lage zu kommen wünsche, von irgend einem der Gefährten borgen zu müssen. Vor allem bitte ich aber um Deine Meinung, denn ich möchte nichts thun, wodurch ich Deine Mißbilligung mir zuzöge. Weil ich für den eigentli-

53 Paul Stoppelberg (1809-1837), studierte an der Universität Dorpat Medizin in den Jahren 18281838, Karl Eduard von Lipharts enger Freund, der an der Italienreise im Jahr 1834 teilnahm, doch er kehrte früher zurück und machte auch bei Krüger in München einen Zwischenstopp. Von Liphart Briefe mit den Eindrücken aus Italien an Stoppelberg aus den Jahren 1835-1837 werden im DSHI
Liphart-Bestand aufbewahrt. Liphart-Bestand aufbewahrt.

4 Johann Julius Friedrich Erdmann (1808-1858), Arzt, Professor an der Universität Dorpat, studierte an der Universität Dorpat Medizin 1827-1833, 1833-1836 Studien in Berlin, danach als Arzt in Wolmar (lett. Valmiera) tätig, seit 1847 Arzt in Dorpat und Universitätsprofessor

55 Fedor Inozemtsev (1802-1869), Chirurg, Medizinwissenschaftler, studierte an der Universitä Dorpat am Professoreninstitut, das Lehrkrafte fur andere Hochschulen des Reichs ausbilden sollte, später Professor an der Universität Moskau. Bekannt war er für seine erste Anwendung ein Äthernarkose im Russischen Reich.

56 Zur und Schiemann, sämtliche mit deutschbaltischem Hintergrund aus seinem Münchener Bekanntenkreis. 
chen Zweck meines hiesigen Aufenthalts fast gar nichts machen kann, denn es geht hier alles so langsam mit dem Hoffmann, und ich kann nich einmal Farben erhalten, obgleich ich sie schon lange bestellt habe ${ }^{57}$, so habe ich mehre Versuche im portraitiren gemacht. Ich wollte, ich könnte sie Dir zeigen. Berg u Schöler haben die ihrigen schon fortgeschickt, und Swerdsjöe ist bald vollendet. Ich will darüber nichts weiter sagen, als daß ich mehr Vertrauen zu mir selbst gefaßt habe, nachdem ich eine bis jetzt mir anklebende Scheu überwunden habe.

Wahl hat eine neue Wohnung bezogen, und zwar von der Madame getrennt. Die Ursache zu dieser Trennung, in die sie ungern endlich willigte, ist ein Brief von seiner Mutter, in dem sie sehr ungehalten ist. Das Verhältniß mit der Kleinen und ihm, allein ganz anders, hat sie schon fünf Wochen vor der Ankunft seines Briefes gewußt. Er hat ihr nun in seiner Antwort versprochen nicht mehr zusammen zu wohnen, im Übrigen ist Alles, wie es war. Wahl fühlt es selbst, daß es so besser ist, und ist sehr zufrieden. Wenn sie nur etwas mehr Verstand besäße, man kann ihr nicht lange zürnen, denn sie ist immer so unendlich gut.

Was die Holzschnitte von $A$. Dürer betrifft, so setzte ich hier die äußersten Preise bei: Leben d. Madonna compl. 20 Blatt 25 fl. ${ }^{58}$ Kleine Passion, 37 Blatt 15 fl. 30 xr, früher 22 fl. grosse Passion 12 Blatt 15 fl. 30 xr, früher 22 fl. ${ }^{59}$ Die zwei kleinen gestochenen Blätter, die Apostel, ${ }^{60}$ die er in Commission hatte, und die mit den Blättern, die Du nicht wolltest, $8 \mathrm{fl}$. kosteten, trennt er nun und läßt sie für $5 \mathrm{fl}$. Wenn Du Aufträge mir geben willst so soll es mich sehr freuen, sie besorgen zu können. Inliegenden Brief bitte ich weiter zu befördern. Ist an mich keiner gekommen? Ich warte mit um so größerer Sehnsucht auf einen, da ich so lange keinen erhalten habe, nemlich aus Dorpat. ${ }^{61}$ Swerdsjöe läßt Stoppelberg ersuchen, ihm zu melden, wenn seine medicinischen Bücher und die Kupfertafeln

$57 \quad$ Krüger hatte sich Enkaustikfarben bestellt.

58 Fl. = Florin = internationale Abkürzung für Gulden, der selbst auf die florentinische Währung zurückgeht. Der Gulden war besonders in Süddeutschland (Rheinischer Gulden) und den Niederlanden verbreitet.

99 Krüger informiert von Liphart über die Preise von Albrecht Dürers bekanntesten Holzschnittserien "Das Leben der Maria , „Die große Passion” und „Die kleine Passion” auf dem Münchener Kunstmark der damals aktiver war als der Bentiner. Dies bekraftigt den Umstand, dass sich Karl Eduard vo tiphart 60 Wahrscheinlich geht es hier um zwei kleine Kupferstiche Dürers (ca. 11,8x7,5 cm), die der Aposte Paulus und Thomas, datiert auf 1514.

fifterkehr mit seiner Verlobten Emilie Rimman, die er nach Dorpat zurückgekehrt auch 1835 ehelichte. von Scarpa $^{62}$ aus Wien ankommen, damit er darüber beruhigt wird. Swerdsjöe u Wahl lassen Dich grüßen. Von mir grüße Stoppelberg, Erdmann, Lanting, Schmidt u Innosemzeff. Leberecht, recht wohl, liebster Liphart, und schreibe mir bald.

Ich bleibe, so lange ich lebe mit der größten Dankbarkeit

Dein ganz ergebener Woldemar Krüger München am 17 Dcbr. 33.

\section{Liebster Liphart!}

Es freut mich sehr, daß ich nicht erst etwas wartete mit dem Abschicken meines letzten Briefes, da ich die Deinigen denselben Nachmittag erhielt, für welche ich hiemit recht vielen Dank sage. An Muth fehlt es mir zwar nicht, allein ich weiß in der That nicht, wie es kommt, daß ich so geringe Lust und Neigung hege, hier zu bleiben. An demselben Tage als Du hier abreistest fühlte ich mich so unbehaglich, und wenn ich ganz allein gewesen wäre, würde ich mich recht unglücklich gemacht haben. An die Rottmanns ${ }^{63}$ habe ich wohl gedacht und auch einmal versucht, Dir eine Landschaft zu zeichnen, es ist aber so schwer und störend, theils der vorübergehenden, theils des fortwährend gar so schlechten Wetters wegen. In den Frühstunden der langen Sommertage würde es besser gehen. Es müßten diese Zeichnungen recht genau gemacht werden, außerdem bringe man im Malen nichts Gutes hervor.

Das ist mir aber jetzt ganz unmöglich. Es will nicht mehr so recht gehen, wie früher, so gar ärgere ich mich jetzt darüber, daß ich wieder in meine alte Wohnung gezogen bin. Kurz, ich wünsche nichts mehr,

62 Antonio Scarpa (1747-1832), bekannter italienischer Anatom und Chirurg, bei dem der Professor der Chirurgie der Universität Dorpat, Johann Christian Moier, auch in Padua studiert hatte. Scarpa Handbücher der Chirurgie mit exakten Zeichnungen (Tabulae nevrologicae, 1794, u. a.) erschiene in mehreren Auflagen.

63 Carl Rottmann (1797-1850), deutscher Maler, Landschaftsmaler, war bekannt für seine mythologisch-allegorischen Landschaftsgemälde. Er lebte und war in München aktiv. Weiterhi gehorte er zu den Kunstlen, die Bestellungen Für Ludwig I. erfullten. 1830-1833 stellte Rottman Durch die Vermittlung des Künstlers und Professors Rhomberg wurde Krüger mit Rottmann bekannt. 
als recht bald von hier fortzukommen. Alle Vorbereitungen dazu sind schon getroffen, und jetzt brenne ich, ich möchte sagen vor Sehnsuch endlich das schöne Land zu sehen. Nimm es mir nicht übel, allein ich wiederhole meine frühere Bitte, und hoffe, Deine Güte wird sie gewähren. Da Du die Geschäfte der Kunst so fleißig studierst, so wird es für mich um so belehrender seyn, mit Dir hernach zusammen reisen zu können. Um Rumohr's italienische Forschungen ${ }^{64}$ will ich mich umsehen, und das Buch zu erhalten suchen statt dieser Rollmanns [?] hier will ich lieber dieselben Gegenstände nach der Wirklichkeit kopieren, wie ich mich aufs Fleißigste bemühen werde, die größtmöglichste Anzahl von Studien zu sammeln. Den Mangel derselben empfinde ich aufs empfindlichste, und ist ein Grund meiner Unzufriedenheit mit mir selbst. Lege es mir nicht übel aus, daß ich nicht bis zum April warten will, bis Du und Paul herkommen, allein ich hoffe und freue mich, daß wir uns dann ganz gewiß in Oberitalien treffen. Ich verspreche mir viel von der Reise. Grüße den lieben, guten Stoppelberg, Erdmann, Innosemzeff. Von Wahl und Madame eine Empfehlung. Lebe recht recht wohl, liebster Liphart, und zürne nicht Deinem für immer ergebenen W. Krüger. München am 18ten Dcbr. 33.

\section{Liebster Liphart}

Du kannst es gewiß glauben, daß es mir unendlich leid ist, Dir mit meiner Bitte um Geld gerade jetzt beschwerlich gefallen zu seyn, indessen bin ich überzeugt, Du zürnst mir nicht. Ich werde $u$ will ja gerne noch warten, bis ein günstigerer Augenblick eintritt. Es ist daher die Abreise ganz unbestimmt, und kann erst dann, wenn alle in Ordnung sind auf einen gewissen Tag festgesetzt werden. Sollte sie sich aber länger, als wir vermuthen, verschieben, so ist beschlossen, so schnell als möglich nach Rom zu kommen, um, wenn auch nur das Ende des Karnevals ${ }^{65}$ daselbst

64 Carl Friedrich von Rumohr (1785-1843), deutscher Kunsthistoriker und Kunstsammler. Rumohrs Abhandlung zur italienischen Kunstgeschichte „Italienische Forschungen”, welche 1827 (I. und II. Band) und 1831 (III. Band) erschien, war innovativ in ihrem quellenkritischen Teil. Rumohr wurde später zu 65 Beim Karnannten von Lipharts, mit dem er seit seinem Berlinaufenthalt 1836 kommunizierte. Feier, die im Zeitraum zwischen Februar und April stattfinden konnte, je nach dem Stand des Mondes. anzusehen, wiewohl es für meine Person die Reise mehr des Nutzens, als des Vergnügens wegen geschehen soll. Nach Mailand können wir jetzt nicht, denn Venedig soll erst mitgenommen werden. Auf keinen Fall will ich auch von irgend einem der Gefährten borgen $u$ wiederhole es nochmals: ich warte gern und bin weit entfernt Dir meinetwegen noch mehr Ungelegenheiten machen zu wollen. Eben so wenig kommt es mir $\mathrm{zu}, \mathrm{zu}$ bestimmen, wie viel ich zu haben wünsche. Ich werde mit dem zufrieden seyn, was Du mir schicken kannst. Denn nie darf ich es vergessen daß ich Deiner Güte ja nur Alles zu danken habe. Indessen fahre ich fort mich im portraitiren zu üben, wenn es mich gleich oft unmüthig macht, daß Auge und Hand noch nicht gleichen Schritt halten können. ${ }^{6}$ Ich verzage aber deshalb nicht. Es freut mich, daß Erdmann an meiner Wenigkeit Theil nimmt.

Für die Besorgung meines Briefes herzlichen Dank, wenn ich doch auch recht bald einen, von einer mir theuren Hand erhielte. Erdmann und den andern herzlichen Gruß. Von Wahl, Swerdsjöe und Madame eine Empfehlung. Lebe recht wohl, liebster Liphart, beginne das neue Jahr recht froh, und wollte Gott, es brächte uns recht bald zusammen, das wäre erst angenehm. Ich bitte nochmals um Entschuldigung und bleibe immer mit Liebe

Dein treuer u dankbarer Woldemar Krüger München am 29 Dcbr. 33.

Madame ist doch ein herzensgutes Kind, sie hat uns am Weihnachtsabend einen Baum ausgeputzt und einen jeden beschenkt, wobei sie selbst außerordentlich vergnügt war. Vernünftig gelenkt, liesse sich wohl mit ihr auskommen, allein es müßte derjenige einen langen u starken Geduldfaden besitzen, wenn einer nemlich mit ihr zusammen leben wollte.
66 Die Darstellung von Menschen wurde in der Zeichenschule der Universität Dorpat nicht unterrichtet, deshalb stellte das Porträtieren für Krüger eine neue Herausforderung dar. 
Liebster Liphart!

Auf Swerdsjoe's Antrieb bin ich genöthiget, Dich wieder ein wenig zu belästigen. Von den fünf ${ }^{67}$, die zusammen nach Italien zu reisen gedachten, ist blos Swerdsjoe der einzige, der bereit ist, mit den übrigen sieht es noch sehr windig aus. Der Doctor ist [...] ganz unzufrieden mit dem zwecklosen hiesigen Aufenthalt, möchte aber auch nicht gern den Herbst und Winter hier verloren haben, aber auch nicht gern allein nach Italien reisen. Er hat mich daher aufgefordert doch fortzugehen, u sich erboten, mir, wenn ich mit meinem Gelde zu kurz käme, das Nöthige vorzustrecken.

Ich habe aber kaum 100 Gulden, u er nur etwa 350, ich trage daher großes Bedenken diesen Antrag anzunehmen bevor ich nicht sicher weiß, wann u wie ich ihm das Seinige wieer erstatten kann. Ich sollte Dich daher bitten, mir recht bald zu antworten, was Du dazu sagst.

Ich habe immer eine große Ängstlichkeit, wie, wo u wann würde ich in Italien von Dir Geld erhalten, und ob es auch richtig an mich gelangte. ${ }^{68}$ Keineswegs mußt Du aber glauben, lieber Liphart, daß ich dadurch Dich nochmals erinnern wollte, an mich zu denken, oder Dich zu belästigen. Ich bleibe ja sehr gern auch bis zu Deiner Ankunft hier, und wenn ich in diesen Tagen etwas unmuthig und unzufrieden war, so hat die vergebliche Erwartung eines Briefes aus Dorpat mit dazu beigetragen jetzt bin ich aber ganz zufrieden. Vielleicht kommst Du früher, als Du anfänglich glaubtest, das würde mich unendlich freuen. Ich hätte Dich jetzt nicht beschwert, allein ich mußte es thun, denn ich hatte es in [...] versprochen was mich jetzt reut. Sei daher so gut, und melde mir, wenn auch nur mit wenigen Zeilen, was Du willst, das ich thue, damit ich auch etwas Gewißes darüber weiß.

Die enkaustischen Farben habe ich erhalten, und zu meiner Zufriedenheit auch die Bereitungsart des Mörtels erfahren ${ }^{69}$, ich muß nun alles, was man mir sagt, auf Treu und Glauben hinnehmen, indessen bin ich doch damit zufrieden, daß man mir es sagt.

67 Siehe Anmerkung 56

68 Krüger wollte sich nicht früher auf die Reise begeben, bis die Übereinkunft bezüglich der Reisekosten sicher war.

Wachsfarben, die bestellt worden waren, und besaß auch das nötige Wissen zur Anfertigung von Mörtel für die Wandmalereien.
Die Zeit bis zum April wird mir gewiß viel schneller vergehen, wenn ich einmal gewiß weiß, daß ich Dich hier erwarten soll. Swerdsjoe bittet ihm doch darüber etwas Bestimmtes wissen zu lassen bei wem seine Sachen deponirt werden, damit erfalls er früher nach Hause zu reisen gedächte, darüber eine Anordnung treffen kann. Er, so wie Wahl und Madame, laßen Dich grüßen. Von mir grüße Stoppelberg recht schön u herzlich, wie auch Erdmann. Ich bitte nochmal nicht auf mich zu zürnen, mir aber recht bald zu antworten. Lebe recht wohl, liebster Liphart und denke bisweilen an Deinen immer dankbaren

Woldemar Krüger

München am 27 Januar 1834

\section{Liebster Liphart!}

Vielen, vielen Dank für Deinen Brief, der mich wieder ermuthigt hat, und mich hoffen läßt, vielleicht recht bald von hier fortzukommen wenn $\mathrm{Du}$ also die Güte haben willst und mir so bald es geht, versteht sich, ohne Dich dadurch zu incommodiren, Geld schickst, so werde ich Dir mit dem größten Danke verpflichtet seyn, und gewiß nicht zögern, sondern sogleich fortreisen. Du hast ganz Recht, daß in zwei Monaten sich schon viel sehen läßt, und ohne Zweifel in Italien für mich von gröBerm Nutzen seyn werden als hier. ${ }^{70}$ Je länger ich hier verweile desto weniger Zeit bleibt mir für Italien übrig, da ohnedieß die Zeit zu der Reise dahin für mich kurz genug ist. Ich richte mich also vorläufig so ein, um gleich nach Empfang des Geldes abzureisen. Leicht könnte es seyn, daß ich ganz allein reise, denn Swerdsjoe scheint mit Nolde, der ganz u gar gemüthskrank ist, reisen zu wollen, und von den übrigen will ich gar nichts sagen.

Mir ist es gleich, und jetzt soll mich gewiß nichts mehr abhalten München zu verlaßen so bald ich es im Stande bin. Ich danke Dir daher

70 Krüger beabsichtigte, die Zeit möglichst effektiv zu verwenden und er zweifelte lange, bevo er sich von der Nützlichkeit der Italienreise überzeugen ließ. 
nochmals für Dein Anerbieten und [...] drauf, Dich in Italien schon irgend wo zu treffen. Veränderung wird mir gut thun und mich zerstreuen, denn ich kann Dir nicht sagen wie mich es quält daß ich aus Dorpat noch keine Nachricht habe.

Die demagogischen Umtriebe anlangend, derenwegen Wahl gesessen haben soll, so verhält sich die Sache anders. Gesessen hat er allerdings 2 Tage in der Polizei, so wie auch Kleist, aber nur in Folge einer Forderung auf Pistolen die er einem hiesigen Artillerielieutenant, mit dem er am 2ten Januar auf einem Balle einen Hendel hatte, machen ließ. Der Offizier weigerte sich, sich auf Pistolen zu stellen, und da die Sache in Güte nicht beigelegt werden konnte, so mengte sich die Polizei hinein, die Gott weiß, durch wen von der Sache in Kenntniß gesetzt worden war, sperrte beide $\mathrm{H}$ ein, u übergab sie nach 2tägigem Arrest dem Stadtgericht. Dieses setzte sie auf Caution in Freiheit, sie warten nun noch, aber unter polizeiliche Aufsicht gesetzt, auf die Entscheidung des Stadtgerichts. Mehr ist an der ganzen Sache nicht. Wahl ist es sehr unangenehm, daß die Sache so entstellt so weit bekannt ist, und er fürchtet seine Mutter habe sie auch schon erfahren und Gott was Arges denken.

Ich habe Rottmann neulich besucht, und von ihm über einige Punkte Italiens, die seiner Meinung nach für den Landschaftsmaler am interessantesten sind, Auskunft erhalten. ${ }^{71}$ Besonders schön hat er die Gegend am Mittelmeere, bei Massa la Spezzia ${ }^{72}$ und die Umgebung [...] gefunden, und der Gegend um Neapel sogar vorgezogen. Dadurch ward in mir [...] das Verlangen recht bald dahin zu kommen wieder rege, und jetzt hoffe ich, wird [...] es bald erfüllt. Swerdsjoe, Wahl u Madame lassen grüßen. Von mir grüße den Stoppelberg, Erdmann u andre. Lebe recht, recht wohl, liebster Liphart, und [...] bisweilen in Liebe an Deinen ganz ergebenen $\mathrm{u}$ dankbaren

Woldemar Krüger

München am 8ten Febr. 1834.

71 Carl Rottmann verbrachte die Jahre 1826-1827 in Italien mit der Aufgabe, Motive zu sammeln und Vorarbeiten für die von Ludwig I. bestellten Wandmalereien für den Hofgarten mit italienischen Themen zu verrichten.

72 Rottmann empfahl Krüger als einen malerischen Ort den ligurischen Strand in Norditalien, wischen La Spezzia und Massa. In diese Region fällt auch der Marmorsteinbruch in Carrara, der seit der Antike bekannt ist.
Liebster Liphart!

Swerdsjoe ist nun schon bald drei Wochen mit Nolde und Berg von hier fort, etwa so auch Schöler, der ist aber allein gereist. Erster hat mir noch aufgetragen, Dich um die Gefälligkeit zu bitten, seine bei Bienemann deponirten Sachen, falls dieser in den Sommerferien nicht in Berlin zu bleiben gedächte, auch nach Hr. Erdmann zu schaffen. Ich warte nun täglich mit großem Verlangen entweder auf Deine persönliche Ankunft, oder doch wenigstens auf eine Nachricht, wann sie erfolgen wird. Dein bisheriges Stillschweigen nehme ich als ein Zeichen, daß es nicht mehr lange dauern kann, bis Du hier bist. Sollte dieses aber durch Umstände doch noch der Fall seyn, so wüßte ich nicht mehr, was vor Ungeduld anfangen. Es will so schon nichts werden was ich vornehme. Ich habe gemalt allein so schlecht ist es mir noch nie gegangen, und trotz dem, daß ich schon oft Pinsel und Palette hingeworfen, alles weggewischt und wieder angefangen habe, so ist es mir nicht gelungen etwas zu Stande zu bringen, womit ich auch nur einigermaßen zufrieden seyn könnte. Es kommt mir vor als wenn ich mit Ungeschicklichkeit geschlagen wäre.

Laß daher liebster Liphart bald von Dir etwas hören, und zwar Gutes. Im nächsten Monat muß ich auch aus dieser Wohnung hinaus denn Rhombergs $^{73}$ verlassen sie, und andere ziehen ein. Ich tröste mich aber damit, daß Du bis dahin schon hier bist. Auf unangenehme Weise hat sich das Wetter geändert, denn auf die schönen warmen Tage ist eine unangenehme kalte Temperatur mit Schnee gefolgt, wenn auch der vor der Sonne schnell verschwindet, so bleibt die Luft immer kalt und rauh, wiewohl sich dieses bei der Unbeständigkeit des hiesigen Klimas auch bald wieder ändern kann. Neues wüßte ich Dir nicht zu melden. Rottmann wird erst im Juni oder Juli nach Griechenland ${ }^{74}$, Du kannst ihn also hier noch treffen. Er hat mir neulich einige hübsche Kompositionen in Aquarell gezeigt die er für die Residenz gemacht; sie werden aber

73 Joseph Anton Rhomberg (1786-1853), Historienmaler, studierte an den Kunstakademien in Wien und München, lebte seit 1823 in München, seit 1827 arbeitete er als Professor der Zeichenlehre an der Münchener Polytechnischen Schule. Krügers Heimstätte in München war eine Wohnung, die Rhomberg gehörte. Die Ehefrau des Professors ist von von Liphart mit einer Lithografie porträtier worden (TKM TR 4679 GR 1388).

74 Carl Rottmans Reise nach Griechenland 1834-1835 war die Vorbereitungsarbeit für die vo Ludwig I. bestellten Fresken mit griechischen Landschaftsansichten sowie für das Sammeln vo Motiven als Zeichnungen und Aquarelle. 
von einem andern gemalt. Noch habe ich gehört, Bodmer ${ }^{75}$ wird alle Fresken und enkaustischen Gemälde der neuen Residenz lithographirt herausgeben. Er hat das Privilegium dazu erhalten. Lebe recht wohl, lieber Liphart, grüße Alle herzlich, besonders den guten Stoppelberg und Erdmann. Vergiß meine obige Bitte nicht. Lebe nochmals wohl ich bleibe für immer mit dem größten Dank verpflichtet

Dein ganz ergebener u treuer Woldemar Krüger. München am 19. März 1834./
Ingrid Sahk: From Tartu (Dorpat) to Italy and Back. Some Thoughts About the Study Trip of Woldemar Friedrich KRÜGer as Reflected IN the LetTers Sent to Karl Eduard von Liphart From 1832 to 1834

Keywords: $19^{\mathrm{Th}}$ Century; Munich; Art Education; Lithography; Wall PAintings; Study TRIPS; Italy

\section{SUMmary:}

The article accompanies the comments and publication of letters written by an Estonian artist Woldemar Friedrich Krüger to his friend Karl Eduard von Liphart, an art collector and expert from Munich between 1832-1834. The main intention of the author has been to provide the reader with the necessary short biography of the Woldemar Krüger and to contextualize the years in which the letters were written. Also the paper aims to open up some subjects and keywords that occur in the letters sent by Krüger to Liphart. The letters that are deposited in the Herder Institute Dokumentesammlung (DSHI) illustrate the early years in the lives of Krüger and Liphart when they both were in their twenties and only in the very beginning with their professional career. Artist Krüger, who was able to study and travel abroad only with the help of the Lipharts family, was especially interested in acquiring technical skills in lithography and encaustic (wax painting). The letters from Munich reveal us a very practically minded and careful personality as Krüger even hesitates before travelling to Italy being afraid that it could lead him away from his routine and practicing. Unfortunately, the letters do not prove whether Krüger attended any official and regular art course during his stay in Munich. However, the letters add valuable information about the developing years of both of the artist Woldemar Krüger and art connoisseur Karl Eduard von Liphart. The correspondence enables us to have a glance at the ideas and acquaintances that they shared and how studying abroad could look like in the $19^{\text {th }}$ century. 


\section{V:}

Ingrid Sahk (MA) is an Estonian art historian interested mainly in the history of graphic art and collections in Estonia in the $19^{\text {th }}$ century as well in other periods. Her recent research and publications involve the history of the collection of prints owned by Karl Eduard von Liphart. She works as a curator in University of Tartu Art Museum, has curated several exhibitions of prints in the museum and has lectured on the history and techniques of graphic art. 